\title{
Identification and molecular characterization of novel anther-specific genes in Oryza sativa $L$. by using cDNA microarray
}

\author{
Makoto Endo ${ }^{1,2, \dagger}$, Tohru Tsuchiya ${ }^{3, \dagger}$, Hiroshi Saito ${ }^{1}$, Hitoshi Matsubara ${ }^{1, \dagger \dagger}$, \\ Hirokazu Hakozaki ${ }^{1}$, Hiromi Masuko ${ }^{1}$, Motoshi Kamada ${ }^{2}$, \\ Atsushi Higashitani ${ }^{2}$, Hideyuki Takahashi ${ }^{2}$, Hiroo Fukuda ${ }^{4,5}$, \\ Taku Demura ${ }^{5}$ and Masao Watanabe ${ }^{1, *}$ \\ ${ }^{1}$ Faculty of Agriculture, Iwate University, 3-18-8 Ueda, Morioka 020-8550, Japan. \\ ${ }^{2}$ Graduate School of Life Sciences, Tohoku University, 2-1-1 Katahira, Sendai 980-8577, Japan. \\ ${ }^{3}$ Life Science Research Center, Mie University, 1515 Kamihama, Tsu 514-8507, Japan. \\ ${ }^{4}$ Department of Biological Sciences, Graduate School of Science, The University of \\ Tokyo, 7-3-1 Hongo, Tokyo 113-0033, Japan. \\ ${ }^{5}$ Plant Science Center, The Institute of Physical and Chemical Research \\ (RIKEN), 1-7-22 Suehiro-cho, Yokohama 230-0045, Japan.
}

(Received 9 July 2004, accepted 1 September 2004)

The complicated genetic pathway regulates the developmental programs of male reproductive organ, anther tissues. To understand these molecular mechanisms, we performed cDNA microarray analyses and in situ hybridization to monitor gene expression patterns during anther development in rice. Microarray analysis of 4,304 cDNA clones revealed that the hybridization signal of $396 \mathrm{cDNA}$ clones (271 non-redundant groups) increased more than six-fold in every stage of the anthers compared with that of leaves. Cluster analysis with the expression data showed that 259 cDNA clones (156 non redundant groups) were specifically or predominantly expressed in anther tissues and were regulated by developmental stagespecific manners in the anther tissues. These co-regulated genes would be important for development of functional anther tissues. Furthermore, we selected several clones for RNA in situ hybridization analysis. From these analyses, we found several novel genes that show temporal and spatial expression patterns during anther development in addition to anther-specific genes reported so far. These results indicate that the genes identified in this experiment are controlled by different programs and are specialized in their developmental and cell types.

Key words: anther-specific genes, in situ hybridization, microarray, Oryza sativa L.

\section{INTRODUCTION}

In higher plants the development of the male gametophyte is a well-programmed and elaborate process that plays a crucial role in plant reproduction. Male gametophytes form within the reproductive floral organ, the stamen. The stamen consists of two morphologically distinct parts, the anther and the filament. The filament is a tube of vascular tissue that anchors the stamen to the flower and serves as a conduit for water and nutrients.

Edited by Yoshibumi Komeda

* Corresponding author. E-mail: nabe@iwate-u.ac.jp

$\dagger$ These two authors are equally contributed to this work.

${ }^{\dagger}$ Current address: Adachi Higashi High School, Iwashiro 9640316, Japan.
In contrast, the anther contains many differentiated tissues and cells (Goldberg et al. 1993). It is of great interest to learn what molecular mechanisms control development of the stamen for understanding sexual reproduction of higher plants. Furthermore, the understanding of the molecular mechanism could be applicable to agriculture such as hybrid seed production by using male sterility.

During anther development, cell differentiation and dehiscence events occur in a precise order (Goldberg et al. 1993). Anther development can be divided into two general phases according to internal morphology (Koltunow et al. 1990; Goldberg et al. 1993). During the first phase, several highly specialized cells and tissues responsible for carrying out non-reproductive functions and reproductive 
functions are established in the anther. The non-reproductive tissues include the epidermis, endothelium, tapetum, circular cell cluster, connective, stomium and vascular bundle. During the second phase, microspore differentiation into pollen grains, enlargement and expanding of anther, elongation of filament, dehiscence, and pollen grain release occur. Various non-reproductive tissues in the anther accomplish these processes during the second phase. For example, the tapetum supports pollen development by secretion of the nutrients and other metabolites, which are constructed from the pollen outer surface and degenerates before dehiscence. The endothelium, the stomium and the connective have important roles in anther dehiscence (Matsui et al. 1999). During anther dehiscence, the anther locules open as a result of stomium cell rupture (Keijzer 1987). Swelling of the epidermis and the endothelium of the anther induce this process. Next, cells of the epidermis and endothelium lose most of their water and shrink. This causes the locule walls to bend outward, and the anther opens to release the pollen grains (Keijzer 1987).

The whole developmental process of the anther is controlled by coordinate gene expression in various specialized tissues and cells (Koltunow et al. 1990; Goldberg et al. 1993). To understand the molecular mechanism of anther development, several anther-specific genes, which were expressed with a specific temporal and spatial manner, have been isolated in several plant species (Jeon et al. 1999; Fourgoux-Nicol et al. 1999; Smith et al. 1990; Tsuchiya et al. 1994; Koltunow et al. 1990; Roberts et al. 1993; Hihara et al. 1996; Wang et al. 2003). However it has been reported that about 10,000 different kinds of transcripts are specific to the anther of tobacco plant (Kamalay and Goldberg 1980; Kamalay and Goldberg 1984), suggesting that the current knowledge of antherspecific transcripts is very poor. Recently, large-scale gene expression analysis, such as microarray and serial analysis of gene expression (SAGE) techniques, has been applied to identify anther- and/or pollen-specific genes in model dicotyledonous plants, Arabidopsis thaliana or Lotus japonicus (Amagai et al. 2003; Lee and Lee 2003; Honys and Twell 2003; Becker et al. 2003; Endo et al. 2002). However, to date, there has been no report to monitor genome-wide gene expression during the anther development in the monocotyledonous plants.

Rice (Oryza sativa L.) has become a model monocot plant because of its relatively small genome size and easiness of transformation (Sasaki and Burr 2000). Recently, the sequencing of its genome has been almost completed, and a large number of ESTs (expressed sequence tags) and full-length cDNA information are accumulating in the public database (Sasaki and Burr 2002; Goff et al. 2002; Yu et al. 2002; Kikuchi et al. 2003; Yazaki et al. 2004). These informatics data will help us to more rapidly understand gene function in rice and other monocot plants. In addition, rice is an important crop which provides stable food for about half of the world's population (Sasaki and Burr 2000). Especially, because the normal pollen development is one of important factors for fertility, it is tightly related to rice yield. Therefore, it is important to analysis gene expression of male gametophyte in rice, not only for understanding the molecular mechanism of anther and pollen development, but also for controlling of the male fertility and yield.

In this study, microarray elements derived from a cDNA library of anther and pistil tissues of $O$. sativa were assembled to identify anther-specific transcripts compared with those of leaf and pistil tissues. Cluster analysis showed that hundreds of cDNA clones were specifically expressed in the anther tissues and were also regulated by developmental stage-specific manners in the anther tissues. RNA in situ hybridization analysis revealed that several cDNA clones were specifically expressed in the anther tissues such as tapetum or epidermal cells. Here, we discussed the possible functions of these genes based on their sequence properties and expression patterns.

\section{MATERIALS AND METHODS}

Plant materials and mRNA isolation Plants of $O$. sativa cv. Koshihikari were grown in a green house. Flower buds were classified into three stages according to bud length and the number of the cells in the male gametophytes (Tsuchiya et al. 1992). Anther and pistil tissues in various stages (A1, A2, A3, P1, P2, and P3) were collected for isolation of RNA, cDNA library construction, and expression analysis, as described below. Leaf tissues (RL), containing leaf blades and leaf sheaths, were harvested at the young growth stage, 3 to 4 leaves stage. For collecting each tissue, rice plants were harvested at the morning, around 10:00 am. Isolation of poly $(\mathrm{A})^{+}$RNA from the each tissues was performed using a FastTrack 2.0 mRNA isolation kit (Invitrogen, San Diego, CA, USA) as described in Takada et al. (2001).

cDNA library construction Two cDNA libraries were constructed from anther and pistil tissues. The anther cDNA library was made as described in Endo et al. (2000). Briefly, double-stranded cDNA was independently synthesized from each mRNA isolated from three stages of anther tissues (RA1, RA2, and RA3) with a $\lambda Z A$ PII cDNA synthesis kit (Stratagene, La Jolla, CA, USA), and each cDNA was ligated into the EcoRI site of $\lambda \mathrm{ZAP}$ II vector (Stratagene). An equal amount of the ligated cDNA derived from each stage was mixed and packaged in vitro using a Gigapack III extract (Stratagene). The phage library was converted to plasmid form by mass excision according to the procedure described by Strat- 
agene. The pistil cDNA library was also made in the same way.

Preparation of the cDNA microarray Preparation of the cDNA microarray was performed as described in Endo et al. (2002). Briefly, two thousands clones and 2,304 clones were picked up arbitrarily from cDNA libraries derived from anther and pistil tissues, respectively. After plasmid DNA isolation, insert cDNA was amplified by PCR using a M13 universal primer set. PCR products were purified using QIAquick 96-column (Qiagen, Basel, Switzerland) and Multiscreen PCR (Millipore, Benford, MA, USA). The purified cDNA insert was mixed with reagent D (Amersham Pharmacia, Uppsala, Sweden), and each cDNA was spotted in duplication on aluminumcoated and DMSO-optimized glass slides using an Array Spotter Generation III (Amersham Pharmacia).

Fluorescent probe preparation, hybridization and scanning Labeling of each poly $(\mathrm{A})^{+}$RNA with Cy3dUTP or Cy5-dUTP and hybridization were performed as previously described by Yazaki et al. (2000). Microarrays were scanned in both the Cy3 and Cy5 channels with a GenePix 4000A Microarray scanner (Axon Instrumental, Foster City, CA, USA).

Data analysis The fluorescence intensity for each fluor and each element was captured by using ArrayGuage (Fuji Film, Tokyo, Japan). The local background was subtracted from the value of each spot on the array. Normalization of $\mathrm{Cy} 3$ and Cy5 signal intensity was performed by adjusting the total signal intensities of the two images. This operation was termed as "global normalization." The signal data of each element in $\mathrm{Cy} 3$ and $\mathrm{Cy} 5$ was calculated according to the following formula: the value of the signal data $=$ (signal intensity of each element)/(total signal intensities) $\times 10^{6}$. This calculated signal data for each element was used for further analysis.

Cluster analysis for identification of anther-specific genes was performed with the Cluster and Tree viewer software program (Eisen et al. 1998).

Sequence analysis The partial nucleotide sequence of the cDNA clones, which were characterized as antherspecific clones by cDNA microarray analysis, was determined by using the dideoxy chain-termination method using a model 310 DNA sequencer (PE Biosystems, Foster City, CA, USA). In order to identify the number of independent anther-specific clones, clustering of the partially determined sequences was performed as previously described in Endo et al. (2002). A homology search was performed against two different databases. First, we searched the KOME (rice full-length cDNA database, (http://cdna01.dna.affrc.go.jp/cDNA/) using the BLASTN program (Altschul et al. 1990).

The partial nucleotide sequences that showed over 95\% identity for more than $100 \mathrm{bp}$ against full-length cDNA clones found in KOME database were considered to be identical to each other. When the cDNA clones did not match the full-length cDNA clones in the KOME database, we performed the BLASTX search against the $\mathrm{nr}$, non-redundant protein database in DDBJ (http:// ddbj.nig.ac.jp).

in situ hybridization analysis In situ hybridization analysis was performed as described in Fujii et al. (2000) with slight modification. Both antisense and sense probes were synthesized using a T3/T7digoxigenin RNA labeling kit (Roche Diagnostics) according to the manufacturer's instructions. Infiltration of flower buds of $O$. sativa in three stages as described above with sodium phosphate buffer ( $\mathrm{pH} 7.5$ ) containing $4 \%$ paraformaldehyde and $0.25 \%$ glutaraldehyde was performed under vacuum for $10 \mathrm{~min}$ two or three times, and subsequent secondary fixation was performed for $2 \mathrm{~h}$. After dehydration of the tissue with an ethanol series and replacement by 2-methyl-2-propanol, it was embedded in Paraplast Plus (Oxford Labware, MO, USA). Sections 8mm-thick were placed on MAS coated glass slides (Matsunami Glass Ind., Osaka, Japan), and baked at $50^{\circ} \mathrm{C}$ over night. The paraplast was removed by immersion in xylene. After rehydration by an ethanol series, sections were incubated in $200 \mathrm{mM} \mathrm{HCl}$ for $20 \mathrm{~min}$ in $100 \mathrm{mM}$ Tris-HCl (pH 7.5) containing proteinase K (Roche Diagnostics, Basel, Switzerland) for $30 \mathrm{~min}$, and in $100 \mathrm{mM}$ triethanolamine $(\mathrm{pH} 8.0)$ containing $0.25 \%$ acetic anhydrate for $10 \mathrm{~min}$. After dehydration, glass slides were vacuum-dried before application of the hybridization solution containing $1 \mathrm{mg} / \mathrm{ml}$ probe. Hybridization was performed in a humid box at $50^{\circ} \mathrm{C}$ for $12 \mathrm{hr}$. Unhybridized probes were washed with an electro-washing method. The glass slides were incubated in in situ buffer I $(100 \mathrm{mM}$ Tris-HCl ( $\mathrm{pH} 7.5), 150 \mathrm{mM} \mathrm{NaCl}$ ) for $10 \mathrm{~min}$ and in in situ buffer I containing $1.5 \%$ blocking reagent (Roche diagnostics) for $60 \mathrm{~min}$. Anti-digoxigenin alkaline phosphataseconjugated antibody (Roche diagnostics) was diluted 1:1000 with in situ buffer I containing $0.1 \%$ tween 20,400 to $500 \mathrm{ml}$ of which was used on each glass slide. The glass slides were incubated for $60 \mathrm{~min}$, and were washed with in situ buffer I three times. Staining of sections was performed with in situ buffer II (100mM Tris-HCl ( $\mathrm{pH}$ 9.5), $100 \mathrm{mM} \mathrm{NaCl}, 50 \mathrm{mM} \mathrm{MgCl}$ ) containing 450 $\mathrm{mg} / \mathrm{ml}$ nitroblue tetrazalium (NBT) and $175 \mathrm{mg} / \mathrm{ml} 5$ bromo-4-chloro-3-indolyl-phosphate (BCIP). The staining reaction was stopped by application of TE buffer (Tris-HCl (pH 7.6), 1 mM EDTA). For microscopic observation, a cover glass slip and DIATEX (Matsunami Glass Ind.) were used. Photographs were taken with a Nikon Eclipse E800 microscope system (Nikon, Tokyo, Japan). 


\section{RESULTS AND DISCUSSION}

Strategy for expression analysis with cDNA microarray Flower buds in stage 1 contained a uninucleate microspore, and the tapetum reached the peak of its development (A1, anther tissues in stage 1 ; $\mathrm{P} 1$; pistil tissues in stage 1). Flower buds in stage 2 contained bi-cellular pollen grains (vegetative cell and generative cell), and tapetum degeneration was seen in anther tissues (A2, anther tissues in stage 2; P2; pistil tissues in stage 2). Flower buds in stage 3 contained tri-cellular pollens (vegetative cell and two sperm cells) and the tapetum disappeared completely from anther tissues (A3, anther tissues in stage 3 ; P3; pistil tissues in stage 3 ). Fig. 1 represents the transverse section of anther at stage 1 to 3 .

To identify anther-specific genes according to development both qualitatively and quantitatively in $O$. sativa, we used the microarray technique to monitor gene expression patterns of 4,304 clones. To increase the reliability of the detected signals, each PCR sample was spotted in duplicate resulting in a total 8,608 data points. When each sample was reverse-transcribed with fluorescent dye, mRNA derived from anther or pistil tissues in different developmental stages (stages 1 to 3 , see Materials and Methods) was labeled with Cy5. In contrast, mRNA from leaf tissue, a vegetative organ, was labeled with Cy3. The samples were labeled with different dyes, then mixed and hybridized simultaneously to a cDNA microarray. After scanning the $\mathrm{Cy} 5$ and $\mathrm{Cy} 3$ channels and global normalization, the $\mathrm{Cy} 5 / \mathrm{Cy} 3$ ratio was calculated using the global normalized data in each element. Because the elements (right and left positions) were spotted twice for each clone as described above, comparison of the Cy5/Cy3 ratio between the right and left duplicated elements was performed. In each clone, when the $\mathrm{Cy} 5 / \mathrm{Cy} 3$ ratio of the right position to the left position ([Cy5/Cy3 ratio of right position] / [Cy5/Cy3 ratio of left position]) ranged from 1/ 3 to 3 , the data of the clones was adopted, and the Cy5 and $\mathrm{Cy} 3$ data averaged between the right and the left on the glass was used for further analysis. In contrast, when the $\mathrm{Cy} 5 / \mathrm{Cy} 3$ ratio of right to left was under $1 / 3$ or over 3 , the data of the clones was eliminated and attributed to experimental errors.

To assess the reproducibility of the microarray analysis, each tissue comparison was performed four times using independently isolated RNA samples as the starting material. Comparison of the $\mathrm{Cy} 5 / \mathrm{Cy} 3$ ratio among the different glass slide glasses (four experiments) in each clone was performed. Following the comparison, when the Cy5/Cy3 data, which ranged from $1 / 3$ to 3 , was observed more than two times, the adopted $\mathrm{Cy} 5$ and $\mathrm{Cy} 3$ data was averaged in each clone.

Identification of clones expressed abundantly in anthers tissues In order to identify clones abundantly expressed in anther tissues, we compared expression data of cDNA clones among anther tissues (stages 1, 2 and 3) and leaf tissues (vegetative control; RL). After comparing the data for each stage of anther tissues (A1, A2, and A3) versus leaf, the number of clones whose anther tissues / leaf tissues ratio was over six-fold or 10-fold was counted (Table 1). The largest difference in transcript profiles was observed at A2 versus $R L$ and A3 versus RL (Table 1).

In our experiment, the genes that were abundantly expressed in anther tissues were defined as clones with a minimum of six-fold up-regulation in their transcript level against the control, leaf tissues. In this study we
(A)

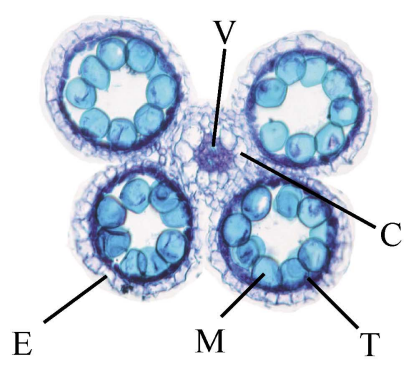

(B)

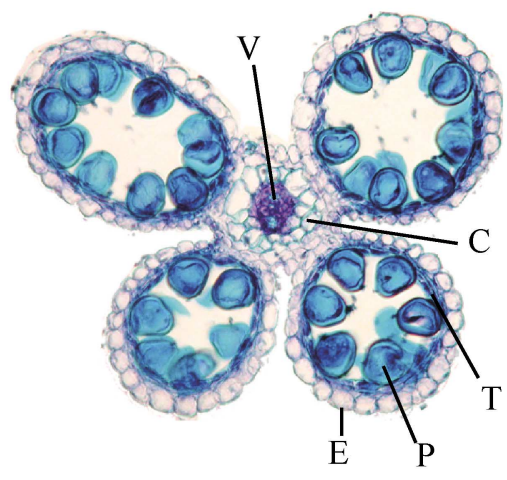

(C)

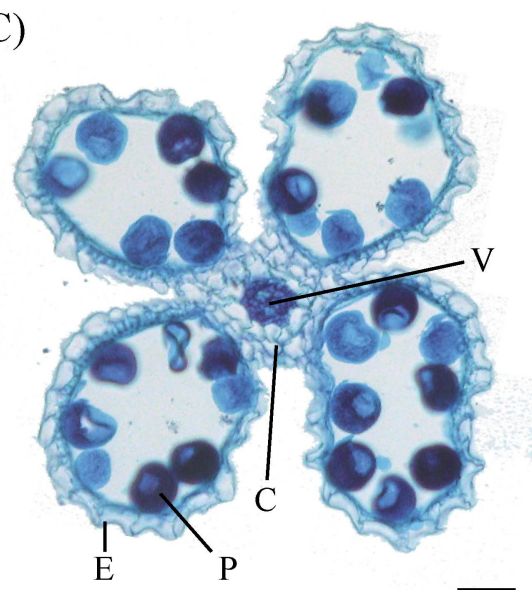

Fig. 1. Cross-section of the anther at different development stages of rice. Each cross-section of anther was stained with toluidine blue. (A) Anther at stage 1. Anther at this stage contained microspore, tapetal cells. (B) Anther at stage 2 . Anther at this stage contained binucleate pollen and tapetal cells. Tapetal cells started to degenerate during stage 2 and 3 . (C) Anther at stage 3 . Anther at this stage contained trinucleate mature pollen grain. Tapetal cells disappeared during stages 2 and 3 . Anther at this stage occurred just before dehisced. C, Connective; E, epidermis; M, microspore; P, pollen grain; T, tapetum; V, vascular bundle. Bar $=50 \mu \mathrm{m}$ 
Table 1. The number of genes abundantly expressed in the anther tissues in each developmental stage.

\begin{tabular}{cccc}
\hline \hline Signal ratio (anther to leaf) & Anther stage 1 & Anther stage 2 & Anther stage 3 \\
\hline 6 to 10 fold & 52 & 60 & 49 \\
more than 10 fold & 98 & 159 & 164 \\
\hline
\end{tabular}

focused on the genes that were abundantly expressed in anther tissues. During anther developmental stages, 396 clones showed more than six-fold up-regulation in at least one of any of the stages. Because the nucleotide sequences of the cDNA clones spotted on the glass slides were not determined, we determined the partial nucleotide sequences of 396 cDNA clones that were abundantly expressed in anther tissues. In order to identify the number of independent cDNA clones, clustering of the nucleotide sequences of the clones was performed. As a result of clustering analysis, 396 clones generated 271 non-redundant groups. Out of 271 non-redundant groups, 52 groups generated contigs that contained at least two cDNA clones, and the remaining 219 groups were singleton. The number of cDNA clones in each group ranged from one to 19 . Most of the groups were small; only eight groups included more than five cDNA sequences. Three hundred seventy two clones out of 396 clones that were abundantly expressed in anther tissues were derived from the anther cDNA library. These results indicated that it was important to construct a specialized cDNA library for identification of an organ-specific gene.

During the generation of non-redundant groups, several groups of the clones were annotated to identical genes, though we could not confirm whether these groups were derived from an identical transcript or an alternative (truncated) transcript. Therefore, these groups

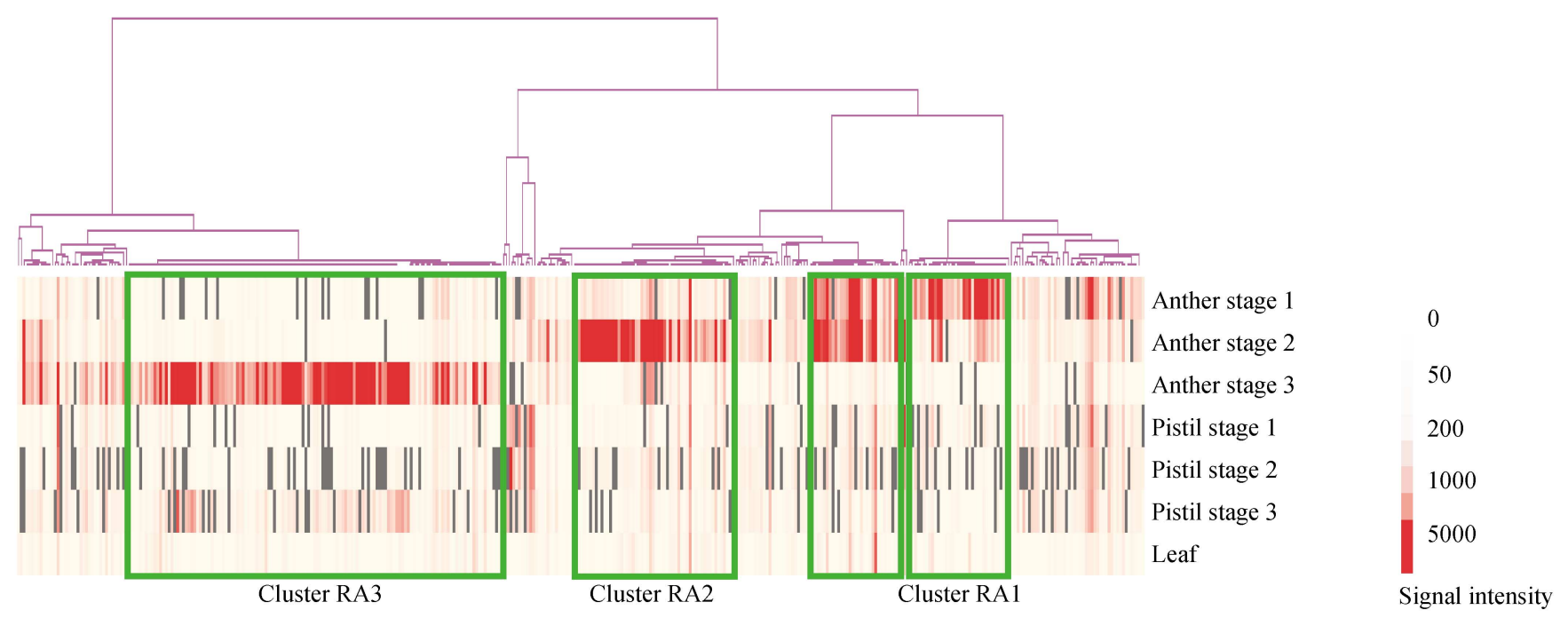

Cluster RA1/2

Fig. 2. Cluster image of 396 highly expressed cDNA in the anther. cDNAs were placed in order using average linkage clustering methods to group similar expression patterns. Horizontal dendrograms indicate the degree of similarity between the expression profile for the cDNA and the developmental stage of organs, respectively. Each column represents the developmental stage of anthers, pistils and leaves. Each row represents the signal intensity of each cDNA clone. In the cluster image, red indicates high signal intensity and gray indicates missing data. The green boxes show areas that correspond to clusters of RA1, RA1/2, RA2 and RA3.

Table 2. The results of similarity search against the public database. The number of anther specific groups that showed similarity to genes of known function and to hypothecical genes that no definition of known function are given.

\begin{tabular}{lcccc}
\hline \multirow{2}{*}{\multicolumn{1}{c}{ Similarity }} & \multicolumn{4}{c}{ Number of groups } \\
\cline { 2 - 5 } & Cluster RA1 & Cluster RA1/2 & Cluster RA2 & Cluster RA3 \\
\hline Genes of known function & 11 & 10 & 19 & 36 \\
Unknown protein & 10 & 6 & 6 & 42 \\
No similarity & 2 & 0 & 3 & 11 \\
Total & 23 & 16 & 28 & 89 \\
\hline
\end{tabular}


Table 3. List of anther-specific genes obtained from cluster analysis

\begin{tabular}{|c|c|c|c|c|c|c|c|c|c|c|}
\hline \multirow{3}{*}{ Group $^{a}$} & \multirow{3}{*}{$\begin{array}{l}\text { No. of } \\
\text { clones }^{b}\end{array}$} & & & & & Expression leve & $\mathrm{el}( \pm$ Standard de & eviation) & & \\
\hline & & Putative function ${ }^{c}$ & $\underset{N^{d}}{\text { Accession }}$ & & Anther & & & Pistil & & Leaf \\
\hline & & & & Stage 1 & Stage 2 & Stage 3 & Stage 1 & Stage 2 & Stage 3 & \\
\hline Clsuter R & & & & & & & & & & \\
\hline Os-8 & 6 & SFFV env & AK058203 & $7452.8( \pm 2922.8)$ & 1125.8 & $36.2( \pm 87.6)$ & $264.6( \pm 348.2)$ & $70.5( \pm 32.7)$ & $41.4( \pm 77.3)$ & $125.2( \pm 539.1)$ \\
\hline Os-14 & 4 & Osc4 protein & AK064717 & $7382.5( \pm 4010.1)$ & 2098.2 & $59.3( \pm 84.2)$ & $387.7( \pm 294.4)$ & $136.1( \pm 150.3)$ & $77.4( \pm 88.8)$ & $115.4( \pm 197.6)$ \\
\hline Os-22 & 2 & $\beta$-ketoacyl-ACP reductase & AK109188 & $806.7( \pm 127.1)$ & $191.3( \pm 34.1)$ & $25 \quad( \pm 6.9)$ & $39.2( \pm 13.6)$ & $25.5( \pm 6.2)$ & $20.6( \pm 9.7)$ & $37.2( \pm 44.3)$ \\
\hline Os-25 & 3 & Acyl carrier protein II & AK058903 & $1224.8( \pm 494.4)$ & $198.4( \pm 98.9)$ & $46.4( \pm 16.7)$ & $241.1( \pm 79.1)$ & $190.8( \pm 75)$ & $106.9( \pm 20.6)$ & $12.6( \pm 21.5)$ \\
\hline Os-39 & 2 & Unknown protein (BAC22270.1) & - & $5842.0( \pm 266.8)$ & $923.1( \pm 269.1)$ & $15.5( \pm 2.8)$ & $192.9( \pm 58)$ & $47.3( \pm 17.7)$ & $26.4( \pm 13.6)$ & $90.1( \pm 139.4)$ \\
\hline Os -40 & 1 & Unknown protein (CAD37124.3) & - & $3150.0( \pm 1042.1)$ & $170.8( \pm 42.8)$ & $31.6( \pm 11.7)$ & $176.8( \pm 75)$ & $40.8( \pm 24.6)$ & $29.5( \pm 9.9)$ & $35.1( \pm 143.5)$ \\
\hline Os- 87 & 1 & YY1 protein & AK107918 & 8007.0 & $868.2( \pm 84)$ & $22.4( \pm 2.5)$ & N. D. * & $52.5( \pm 20.9)$ & $150.3( \pm 150.7)$ & $84.9( \pm 144.6)$ \\
\hline Os-91 & 1 & Unknown protein & AK106664 & $3792.0( \pm 1741.8)$ & $145.2( \pm 39.1)$ & $86.9( \pm 61.7)$ & $364.4( \pm 163.6)$ & $158.3( \pm 96.1)$ & $91.7( \pm 36.3)$ & $280.9( \pm 75.4)$ \\
\hline Os-97 & 1 & No similarity & - & $925.2( \pm 251.3)$ & $153.9( \pm 13.6)$ & $64.3( \pm 10.9)$ & $58.6( \pm 19.7)$ & $44.7( \pm 19.7)$ & $78.2( \pm 20.4)$ & $96.8( \pm 71.7)$ \\
\hline Os-99 & 1 & Unknown protein & AK069589 & $761.6( \pm 298.1)$ & $78.1( \pm 12.7)$ & $59.3( \pm 12.8)$ & $52.2( \pm 8.2)$ & $25.0( \pm 9.2)$ & N. D.* & $21 \quad( \pm 71.2)$ \\
\hline Os-108 & 1 & No similarity & - & $541.6( \pm 262.9)$ & $81.1( \pm 17.9)$ & $15.2( \pm 2.8)$ & $23.2( \pm 9.4)$ & N. D.* & $11.2( \pm 4.9)$ & $11.6( \pm 71.3)$ \\
\hline Os-149 & 1 & Unknown protein & AK064700 & $432.1( \pm 79)$ & $13.3( \pm 10)$ & $17.5( \pm 14)$ & N. D.* & N. D.* & $12.5( \pm 5.3)$ & $29.3( \pm 67.9)$ \\
\hline Os-222 & 1 & Hexokinase & AK067988 & $1577.0( \pm 353)$ & $170.3( \pm 25.6)$ & $33.1( \pm 4.3)$ & $100.4( \pm 23.1)$ & $108.7( \pm 105.8)$ & $66.6( \pm 19.8)$ & $96 \quad( \pm 20.8)$ \\
\hline Os-230 & 1 & bHLH transcription factor & AK106761 & $202.2( \pm 34.5)$ & $58.6( \pm 14.9)$ & $39.6( \pm 13.9)$ & $17.9( \pm 8.2)$ & $12.2( \pm 5.4)$ & $11.8( \pm 7.1)$ & $6.7( \pm 28.6)$ \\
\hline Os-239 & 1 & Unknown protein (AAD12690.1) & _- & $655.4( \pm 127.6)$ & $62.2( \pm 26.2)$ & $16.2( \pm 5.1)$ & $43.1( \pm 9.3)$ & N. D.* & $22.9( \pm 10.8)$ & $30.3( \pm 28.4)$ \\
\hline Os-287 & 1 & Ribosomal protein L5 & AK065268 & $428.7( \pm 101.0)$ & $44.5( \pm 7.2)$ & $20.5( \pm 5.0)$ & $55.9( \pm 16.4)$ & $51.7( \pm 20.7)$ & $53.7( \pm 13.6)$ & $42.1( \pm 42.2)$ \\
\hline Os-288 & 1 & bZIP family transcription factor & AK072267 & $432.9( \pm 198.8)$ & $20.6( \pm 8.3)$ & N. D.* & $30.6( \pm 11.4)$ & $7.8( \pm 1.9)$ & $9.1( \pm 7.2)$ & $8.7( \pm 45.9)$ \\
\hline Os-335 & 1 & Unknown protein & AK106780 & 1416.0 & $166.3( \pm 29.5)$ & $29.3( \pm 11.4)$ & $161.5( \pm 69.8)$ & N. D.* & N. D.* & $18.6( \pm 49.4)$ \\
\hline Os-344 & 1 & Dihydroflavonol reductase & AK099770 & $2675.0( \pm 983.7)$ & $20.6( \pm 10.1)$ & $15.3( \pm 19.4)$ & $94.0( \pm 36.3)$ & N. D.* & $20.7( \pm 8.8)$ & $13.5( \pm 54.6)$ \\
\hline Os-352 & 1 & Unknown protein & AK062232 & 1539.0 & $147.8( \pm 43.2)$ & $23.9( \pm 14.6)$ & N. D.* & $126.4( \pm 61.9)$ & N. D.* & $16.1( \pm 53.9)$ \\
\hline Os-365 & 1 & Cinnamoyl CoA reductase & AK106870 & $1990.0( \pm 26.3)$ & $373.9( \pm 101.4)$ & $18.1( \pm 8.8)$ & $69.5( \pm 51.6)$ & $34.1( \pm 8.6)$ & $20.6( \pm 23.1)$ & $5.8( \pm 51.2)$ \\
\hline Os-395 & 1 & Sucrose synthase 2 & AK072074 & 1445.0 & $194.6( \pm 181.8)$ & $165.7( \pm 89.0)$ & $383.6( \pm 237.2)$ & $363.3( \pm 153.3)$ & $196.7( \pm 103.8)$ & $70.7( \pm 42.4)$ \\
\hline Os-396 & 1 & Unknown protein (AL731599-14) & - & $668.1( \pm 91.3)$ & $25.3( \pm 22.6)$ & $17.9( \pm 13.8)$ & N. D.* & $89.1( \pm 49.4)$ & $161.9( \pm 62)$ & $33.2( \pm 335)$ \\
\hline Clsuter R & $\mathrm{RA} 1 / 2$ & & & & & & & & & \\
\hline Os-3 & 9 & Osc6 protein & AK064672 & $5203.1( \pm 3001.8)$ & 9815.5 & $185.1( \pm 240.6)$ & $495.1( \pm 656.7)$ & $734.6( \pm 761.6)$ & $329 \quad( \pm 555.4)$ & 504.6 \\
\hline Os-13 & 3 & Unknown protein & AK062834 & $3022.3( \pm 668.5)$ & $3780.3( \pm 934.6)$ & $84.6( \pm 76.6)$ & $463.3( \pm 241.9)$ & $389.8( \pm 195.5)$ & $178.2( \pm 106.1)$ & $178.1( \pm 133.6)$ \\
\hline Os-16 & 4 & Proline-rich protein APG & AK106778 & $1186.0( \pm 648.4)$ & $1788.3( \pm 932.2)$ & $25.2( \pm 8.1)$ & $99.6( \pm 52.3)$ & $128.6( \pm 84.2)$ & $81.5( \pm 39.1)$ & $60.5( \pm 66.4)$ \\
\hline Os-27 & 2 & CER1-like protein & AK066386 & 1012.5 & $1899.0( \pm 545.1)$ & $141.2( \pm 50.8)$ & $216.4( \pm 102.2)$ & $218.1( \pm 182.3)$ & $77.3( \pm 29.3)$ & $52.4( \pm 34.3)$ \\
\hline Os-33 & 2 & OsRAFTIN & AK120942 & $1147.0( \pm 281.6)$ & $1774.0( \pm 687.1)$ & $34.1( \pm 10.8)$ & N. D.* & $57.2( \pm 14.2)$ & $24.3( \pm 9.1)$ & $11.4( \pm 17.7)$ \\
\hline Os-56 & 2 & Unknown protein (AAP21417.1) & - & $1893.0( \pm 446.9)$ & $3597.0( \pm 1080.9)$ & $74.5( \pm 27.6)$ & $196.1( \pm 96.7)$ & $548.5( \pm 300.9)$ & $248.9( \pm 120.4)$ & $105.0( \pm 120.2)$ \\
\hline Os-82 & 1 & Osc6 protein & AK064672 & 1608.0 & $3929.0( \pm 939.5)$ & $45.7( \pm 9.3)$ & $76.7( \pm 31.4)$ & $186.4( \pm 80)$ & $79.9( \pm 24.2)$ & $191.9( \pm 56.3)$ \\
\hline Os-84 & 1 & Unknown protein & AK068537 & $154.9( \pm 39.6)$ & $287.2( \pm 27.7)$ & $39.3( \pm 2)$ & $36.7( \pm 6.5)$ & $30.7( \pm 11.5)$ & $26.7( \pm 6.4)$ & $26.6( \pm 19.2)$ \\
\hline Os-95 & 1 & Proline-rich protein & AK058218 & $285.4( \pm 58.5)$ & $414.1( \pm 121.9)$ & $16.9( \pm 4.1)$ & $115.7( \pm 62.5)$ & N. D.* & $15.7( \pm 6.4)$ & $67.9( \pm 51.9)$ \\
\hline Os-131 & 1 & Unknown protein (BAC55659.1) & - & $1227.0( \pm 273.5)$ & $1319.0( \pm 295.3)$ & $176.8( \pm 36.2)$ & $354.5( \pm 153.5)$ & $233.4( \pm 114.8)$ & $193.6( \pm 44)$ & $89.1( \pm 54.5)$ \\
\hline Os-189 & 1 & Unknown protein (CAE05359.3) & - & $1528.0( \pm 316.9)$ & $2511.0( \pm 530.5)$ & $59.1( \pm 20.4)$ & $236.5( \pm 123.2)$ & $233.5( \pm 77.6)$ & $115.1( \pm 44.4)$ & $165.9( \pm 96.4)$ \\
\hline Os-193 & 1 & 3-hydroxy-3-methylglutaryl-CoA synthase & AK071039 & 1604.0 & $1555.0( \pm 465.8)$ & $68.3( \pm 19.4)$ & $294.3( \pm 157.3)$ & $209.1( \pm 87.7)$ & $175.6( \pm 64.7)$ & $62.1( \pm 64.4)$ \\
\hline Os-249 & 1 & Osc6 protein & AK064672 & 4206.0 & $6346.0( \pm 1303.2)$ & $189.6( \pm 21.2)$ & $601.3( \pm 151.6)$ & $824.2( \pm 386.1)$ & $561.9( \pm 182.3)$ & 737.1 \\
\hline Os-262 & 1 & Mammalian MHC III region protein G9a & AK067187 & $491.8( \pm 138.6)$ & $490.4( \pm 179.1)$ & $51.8( \pm 14.5)$ & $59.9( \pm 23.9)$ & $67.7( \pm 14.4)$ & $75.8( \pm 14.7)$ & $25.6( \pm 25.7)$ \\
\hline Os-269 & 1 & Phytochelatin synthetase-like protein & AK070472 & $192.1( \pm 41.2)$ & $235.8( \pm 38.3)$ & $25.5( \pm 4.9)$ & $56.4( \pm 12)$ & $51.5( \pm 22.2)$ & $42.5( \pm 13.7)$ & $53.3( \pm 37.0)$ \\
\hline Os-284 & 1 & Unknown protein & AK100664 & 1045.0 & $1577.0( \pm 599.2)$ & $33.0( \pm 7.7)$ & $96.9( \pm 52.6)$ & $165.1( \pm 61.2)$ & $94.2( \pm 43.2)$ & $22.4( \pm 19.3)$ \\
\hline Clsuter R & & & & & & & & & & \\
\hline Os-2 & 9 & Unknown protein & AK105620 & $354.7( \pm 165.9)$ & $4942.1( \pm 2298.2)$ & $26.8( \pm 25)$ & $57 \quad( \pm 45.8)$ & $180.2( \pm 91.5)$ & $54.7( \pm 33.4)$ & $51.9( \pm 94.4)$ \\
\hline Os-4 & 8 & Unknown protein & AK069454 & $730.4( \pm 533.9)$ & $7093.9( \pm 4443.3)$ & 1033.5 & $231.7( \pm 329.7)$ & $381 \quad( \pm 326.9)$ & $272.3( \pm 231.1)$ & 155.4 \\
\hline Os-6 & 7 & Proline-rich protein & AK059665 & $289.8( \pm 128.1)$ & $4506.1( \pm 1763.9)$ & $23.6( \pm 9.5)$ & $70.5( \pm 36.1)$ & $130.9( \pm 64.2)$ & $29.4( \pm 19.4)$ & $34.9( \pm 35.4)$ \\
\hline Os-12 & 2 & Unknown protein & AK070921 & 1926.8 & 8518.4 & $862.4( \pm 837.2)$ & $1055.1( \pm 1084.5)$ & $759.1( \pm 917.5)$ & $522.4( \pm 560.4)$ & 716.6 \\
\hline Os-15 & 4 & Lipid transfer protein (AAK28533.1) & - & $192.8( \pm 87.4)$ & $1362.5( \pm 693.5)$ & $37.7( \pm 17)$ & $51.5( \pm 37.6)$ & $102.7( \pm 74.7)$ & $90.1( \pm 58.7)$ & $145.0( \pm 104.7)$ \\
\hline Os-18 & 3 & Hypothetical protein (AL606453-12) & - & $55.8( \pm 29)$ & $1210.2( \pm 478.5)$ & $158.9( \pm 55.9)$ & $61.6( \pm 57.3)$ & $83.2( \pm 62.3)$ & $76.2( \pm 53)$ & $85.0( \pm 68.3)$ \\
\hline Os-21 & 2 & Anther-specific protein & AK070978 & $63.9( \pm 32)$ & $6281.5( \pm 1327.3)$ & $217.5( \pm 49)$ & $50.1( \pm 35.8)$ & $158.9( \pm 76.7)$ & $103.3( \pm 36.9)$ & $71.2( \pm 95.1)$ \\
\hline Os-62 & 1 & $\mathrm{RP}$ protein - human & AK111873 & $110.5( \pm 23.3)$ & $549.7( \pm 202.8)$ & $80.1( \pm 15.8)$ & $72 \quad( \pm 27.4)$ & $82.6( \pm 32.5)$ & $67.4( \pm 24.9)$ & $76.8( \pm 31.2)$ \\
\hline Os-76 & 1 & No similarity & - & $768.4( \pm 191.1)$ & $4707.0( \pm 1584.6)$ & $440.8( \pm 163.1)$ & $722.5( \pm 371)$ & $798.6( \pm 371)$ & $554.7( \pm 180.8)$ & 565.8 \\
\hline Os-92 & 1 & Anther-specific protein & AK070978 & $49.5( \pm 8.6)$ & $3445.0( \pm 1161.5)$ & $113.1( \pm 37.4)$ & $43.3( \pm 16.3)$ & $135.0( \pm 77.2)$ & $86.2( \pm 29.1)$ & $323.4( \pm 175.9)$ \\
\hline Os-117 & 1 & Cytochrome P450 (AP002484) & - & $152.2( \pm 28.5)$ & $1750.0( \pm 365.3)$ & $28.5( \pm 5.9)$ & $74.0( \pm 40.2)$ & $64.5( \pm 45)$ & $43.6( \pm 26.5)$ & $91.5( \pm 47.5)$ \\
\hline Os-130 & 1 & Lysosomal acid lipase & AK100511 & 245.5 & $3963.0( \pm 1042.6)$ & $306.6( \pm 62.5)$ & $116.4( \pm 32.2)$ & $158.1( \pm 47.1)$ & $116.3( \pm 32.2)$ & $110.2( \pm 27.2)$ \\
\hline Os-136 & 1 & $\beta$-galactosidase protein (AC091749) & - & $105.2( \pm 22.9)$ & $834.6( \pm 184.4)$ & $60.8( \pm 8.3)$ & $118.7( \pm 65.8)$ & $72.6( \pm 39.1)$ & $65.1( \pm 7.4)$ & $106.7( \pm 61.7)$ \\
\hline Os-139 & 1 & Anther-specific protein & AK070978 & $48.4( \pm 9.7)$ & $2855.0( \pm 771.5)$ & $108.3( \pm 19.5)$ & $71.7( \pm 30.5)$ & $109.6( \pm 17.5)$ & $84.9( \pm 20.7)$ & $221.8( \pm 88.2)$ \\
\hline Os-147 & 1 & $\beta$-ketoacyl-ACP synthase & AK067275 & $365.0( \pm 78.4)$ & $1588.0( \pm 474.8)$ & $111.4( \pm 18.3)$ & $211.2( \pm 106.4)$ & $207.8( \pm 89.6)$ & $154.5( \pm 45.3)$ & $144.0( \pm 53.3)$ \\
\hline Os-196 & 1 & Ferredoxin-sulfite reductase & AK073969 & $150.1( \pm 54.9)$ & $1138.0( \pm 385.5)$ & $49.2( \pm 8.2)$ & $107.3( \pm 42.9)$ & $93.2( \pm 38.8)$ & $71.2( \pm 22.9)$ & $111.6( \pm 79.9)$ \\
\hline Os-209 & 1 & APG protein & AK058562 & $185.4( \pm 54.3)$ & $578.6( \pm 191.5)$ & $34.7( \pm 6.8)$ & $47.0( \pm 21.5)$ & N. D.* & $44.2( \pm 32.3)$ & $23.7( \pm 21.5)$ \\
\hline Os-211 & 1 & Pollen allergen-like protein & AK059231 & N. D.* & $1505.0( \pm 306.1)$ & $25.0( \pm 4.7)$ & $227.9( \pm 76.1)$ & $212.2( \pm 99.1)$ & $118.9( \pm 62.8)$ & $24.1( \pm 20.8)$ \\
\hline Os-223 & 1 & Ribosomal protein L28 & AK066599 & $977.3( \pm 214.5)$ & $7524.0( \pm 841.1)$ & $917.6( \pm 193.8)$ & $512.1( \pm 176.4)$ & $757 \quad( \pm 330.5)$ & $605.9( \pm 183.8)$ & $314.5( \pm 104.7)$ \\
\hline Os-275 & 1 & Unknown protein & AK121167 & $835.1( \pm 410.1)$ & $13340.0( \pm 3728.9)$ & $1633.0( \pm 338.0)$ & $76.6( \pm 17.1)$ & $359.8( \pm 230.3)$ & $310.5( \pm 86.6)$ & $87.2( \pm 31.5)$ \\
\hline Os-277 & 1 & Unknown protein & AK101261 & $144.3( \pm 30.8)$ & $757.0( \pm 254.8)$ & $115.7( \pm 21.9)$ & $116.4( \pm 62.1)$ & $107.8( \pm 35.2)$ & $96.7( \pm 23.2)$ & $128.1( \pm 81.8)$ \\
\hline Os-290 & 1 & OsFEN-1 & AK060623 & $474.7( \pm 133.8)$ & $6380.0( \pm 3492.9)$ & $10.8( \pm 6.4)$ & $33.6( \pm 20.8)$ & N. D.* & N. D.* & $22.7( \pm 21.2)$ \\
\hline Os-298 & 1 & Phosphate transport protein & AK107027 & $7.2( \pm 2.5)$ & $384.9( \pm 92.8)$ & $41.2( \pm 6.9)$ & $10.1( \pm 4.7)$ & N. D.* & $37.4( \pm 9.3)$ & $20.9( \pm 15.5)$ \\
\hline Os-300 & 1 & Coated vesicle membrane protein (AY040079-1) & - & $15.2( \pm 5.2)$ & $567.1( \pm 361.7)$ & $45.0( \pm 14.8)$ & N. D.* & N. D.* & $19.7( \pm 8.8)$ & $6.4( \pm 11.8)$ \\
\hline Os-342 & 1 & No similarity & - & N. D.* & $252.5( \pm 112.7)$ & $9.2( \pm 2.8)$ & $60.0( \pm 37.6)$ & $25.6( \pm 9.2)$ & N. D.* & $10.2( \pm 14.6)$ \\
\hline Os-348 & 1 & UDP-galactose-4-epimerase & AK073610 & $58.6( \pm 15.2)$ & $268.7( \pm 57.1)$ & $17.6( \pm 7.5)$ & $23.8( \pm 31.5)$ & $23.2( \pm 4.6)$ & $27.9( \pm 20.7)$ & $32.3( \pm 28.9)$ \\
\hline Os-350 & 1 & No similarity & - & $45.3( \pm 12)$ & $529.4( \pm 213.2)$ & $12.8( \pm 5.9)$ & N. D.* & $53.9( \pm 30.1)$ & $19.9( \pm 6.1)$ & $16.9( \pm 19.9)$ \\
\hline Os-369 & 1 & Unknown protein & AK058236 & $126.9( \pm 26.3)$ & $954.0( \pm 326.9)$ & $121.6( \pm 27.7)$ & $90.7( \pm 56)$ & N. D.* & $139.7( \pm 60.1)$ & $36.3( \pm 59.3)$ \\
\hline Clsuter $\mathrm{R}$ & RA3 & & & & & & & & & \\
\hline Os-1 & 19 & No similarity & - & $62.7( \pm 174.1)$ & $41.8( \pm 71.1)$ & $10249.9( \pm 5648.0)$ & $36.8( \pm 45.7)$ & $77.4( \pm 68.4)$ & $1007.9( \pm 720.2)$ & $49.8( \pm 66.6)$ \\
\hline Os-5 & 7 & Unknown protein (CAE03779.1) & - & $221.8( \pm 298.5)$ & $63.0( \pm 57.9)$ & $5628.0( \pm 3631)$ & $145.8( \pm 170.8)$ & $218.6( \pm 240.8)$ & $482.1( \pm 313.2)$ & $92 \quad( \pm 107.6)$ \\
\hline Os-10 & 3 & OsGA2ox1 (BAB40934.1) & - & $43.7( \pm 29.3)$ & $142.5( \pm 45.9)$ & $1588.7( \pm 459.2)$ & $21.4( \pm 13.9)$ & $20.6( \pm 8.2)$ & $109.8( \pm 61)$ & $34.6( \pm 46.9)$ \\
\hline Os-11 & 4 & Pollen allergen Cyn $\mathrm{d}$ II, group II & AK111098 & $54.7( \pm 43.3)$ & $40.2( \pm 32.1)$ & $3929.3( \pm 2647)$ & $64.6( \pm 51.3)$ & $61.4( \pm 41.4)$ & $278.6( \pm 150.1)$ & 149.6 \\
\hline Os-17 & 3 & $\beta$-expansin EXPB1 & AK072792 & $77.8( \pm 39.9)$ & $90.3( \pm 52.4)$ & $3897.3( \pm 1729.2)$ & $73.2( \pm 62.3)$ & $63.2( \pm 46)$ & $289.1( \pm 131.0)$ & $52.3( \pm 65.6)$ \\
\hline Os-26 & 3 & Unknown protein & AK064756 & $73.9( \pm 66.9)$ & $39.2( \pm 48.7)$ & $6300.7( \pm 1388)$ & $94.3( \pm 162.1)$ & $138.9( \pm 129.6)$ & $429.4( \pm 227.0)$ & 190.3 \\
\hline Os-28 & 2 & Unknown protein & AK100437 & $22.8( \pm 5.7)$ & $57.2( \pm 133.7)$ & $5021.0( \pm 1344.4)$ & $22.3( \pm 14.8)$ & $34.7( \pm 17.9)$ & $287.4( \pm 41.8)$ & $70.7( \pm 386)$ \\
\hline Os-29 & 2 & Unknown protein & AK101158 & $23.4( \pm 8.4)$ & $16.4( \pm 4.7)$ & $2797.6( \pm 2109.7)$ & $28.8( \pm 24.3)$ & $23.5( \pm 18.1)$ & $102.8( \pm 67.7)$ & $24.6( \pm 28)$ \\
\hline Os-30 & 2 & Unknown protein & AK107558 & $65.7( \pm 44.1)$ & $65.9( \pm 91.8)$ & $2853.5( \pm 1180.6)$ & $72.2( \pm 47.5)$ & $63.3( \pm 31.2)$ & $186.0( \pm 70.3)$ & $93.6( \pm 143.8)$ \\
\hline
\end{tabular}




\begin{tabular}{|c|c|c|}
\hline Os-32 & 2 & Unknown protein \\
\hline Os-37 & 2 & Unknown protein \\
\hline Os-38 & 2 & Actin-depolymerizing factor \\
\hline Os-42 & 2 & $\beta$-expansin EXPB9 \\
\hline Os-48 & 2 & Unknown protein \\
\hline Os-50 & 2 & No similarity \\
\hline Os-55 & 2 & Pollen allergen $P h l p$ II \\
\hline Os-36 & 1 & No similarity \\
\hline Os-41 & 1 & Unknown protein \\
\hline Os-9 & 1 & Unknown protein (CAE03778.1) \\
\hline Os-57 & 1 & Actin \\
\hline Os-63 & 1 & Pollen allergen Lol $p$ IIA \\
\hline Os-65 & 1 & Unknown protein \\
\hline Os-67 & 1 & 14-3-3-like protein \\
\hline Os-68 & 1 & Unknown protein \\
\hline Os-75 & 1 & LIM domain protein \\
\hline Os-78 & 1 & Unknown protein \\
\hline Os-79 & 1 & Isoamylase-type starch debranching enzyme ISO3 \\
\hline Os-86 & 1 & No similarity \\
\hline Os- 88 & 1 & Unknown protein \\
\hline Os-89 & 1 & $\beta$-amylase \\
\hline Os-100 & 1 & Unknown protein \\
\hline Os-104 & 1 & Ubiquitin carboxyl-terminal hydrolase (BAB56080.1) \\
\hline Os-105 & 1 & Unknown protein \\
\hline Os-106 & 1 & nitrate-induced NOI protein (AAC03022.1) \\
\hline Os-107 & 1 & Unknown protein \\
\hline Os-110 & 1 & DNA gyrase A chain \\
\hline Os-113 & 1 & Unknown protein \\
\hline Os-124 & 1 & Rho GDP-dissociation inhibitor 1 \\
\hline Os-125 & 1 & Unknown protein \\
\hline Os-135 & 1 & Unknown protein \\
\hline Os-137 & 1 & Rho GDP-dissociation inhibitor 1 \\
\hline Os-148 & 1 & Inorganic pyrophosphatase \\
\hline Os-150 & 1 & No similarity \\
\hline Os-154 & 1 & RNA binding protein \\
\hline Os-162 & 1 & $\mathrm{Ca}^{2+}$-transporting ATPase \\
\hline Os-163 & 1 & UDP-glucose pyrophosphorylase \\
\hline Os-169 & 1 & Unknown protein \\
\hline Os-178 & 1 & Unknown protein \\
\hline Os-187 & 1 & Unknown protein \\
\hline Os-201 & 1 & Unknown protein \\
\hline Os-204 & 1 & Actin-depolymerizing factor \\
\hline Os-208 & 1 & Unknown protein \\
\hline Os-210 & 1 & Unknown protein \\
\hline Os-213 & 1 & Malate dehydrogenase \\
\hline Os-217 & 1 & Pollen-specific protein $\mathrm{Bp} 10$ \\
\hline Os-218 & 1 & Unknown protein \\
\hline Os-224 & 1 & Unknown protein \\
\hline Os-228 & 1 & Peroxidase \\
\hline Os-229 & 1 & LIM domain protein \\
\hline Os-231 & 1 & No similarity \\
\hline Os-232 & 1 & GDP dissociation inhibitor \\
\hline Os-233 & 1 & Unknown protein \\
\hline Os-234 & 1 & No similarity \\
\hline Os-247 & 1 & EPPT protein \\
\hline Os-252 & 1 & No similarity \\
\hline Os-256 & 1 & Unknown protein \\
\hline Os-257 & 1 & Glycerophosphodiester phosphodiesterase \\
\hline Os-260 & 1 & $\beta$-fructofuranosidase \\
\hline Os-278 & 1 & Unknown protein \\
\hline Os-281 & 1 & No similarity \\
\hline Os-282 & 1 & Plasma membrane intrinsic protein 2 PIP2 \\
\hline Os-283 & 1 & Putative Cycloartenol Synthase protein (BAD02986.1) \\
\hline Os-285 & 1 & Unknown protein \\
\hline Os-292 & 1 & Unknown protein \\
\hline Os-293 & 1 & Unknown protein \\
\hline Os-295 & 1 & Unknown protein \\
\hline Os-303 & 1 & Unknown protein \\
\hline Os-309 & 1 & Polygalacturonase \\
\hline Os-310 & 1 & Unknown protein \\
\hline Os-313 & 1 & Putative cellulose synthase-like protein (BAC80027.1) \\
\hline Os-314 & 1 & No similarity \\
\hline Os-323 & 1 & Unknown protein \\
\hline Os-326 & 1 & Cytochrome P450 \\
\hline Os-331 & 1 & Unknown protein \\
\hline Os-333 & 1 & Unknown protein \\
\hline Os-343 & 1 & Unknown protein \\
\hline Os-349 & 1 & No similarity \\
\hline Os-359 & 1 & Unknown protein \\
\hline Os-382 & 1 & ATP/ADP translocator \\
\hline
\end{tabular}

AK071781 $42.9( \pm 18.7)$

AK069605 $54.2( \pm 17.5)$

AK070187 $28.4( \pm 12.2)$

AK070815 $188.9( \pm 194.6)$ $27.7( \pm 9.2)$

AK069922 $31.5( \pm 15.3)$

$31.1( \pm 10.9)$

AK069940 $138.7( \pm 49.8)$

$191 \quad( \pm 29.4)$

$\begin{array}{ll}\text { AK100267 } & \text { N. D.* } \\ \text { AK121208 } & 40.0( \pm 9.4)\end{array}$

AK120793 $24.0( \pm 8.7)$

AK068248 $755.5( \pm 268.9)$

AK103432 $455.8( \pm 66.5)$

AK072520 $30.1( \pm 10.6)$

AK070386 $22.9( \pm 5.6)$

AK101554 $96.7( \pm 83.8)$

$96.7( \pm 83.8)$
$38.9( \pm 10.5)$

AK069408 $70.2( \pm 17.3)$

AK067249 $24.8( \pm 7.5)$

AK064912 $45.6(+15.4)$

$45.6( \pm 15.4)$
$27.0( \pm 18.1)$

AK099091 $192.6( \pm 65.7)$

$23.0( \pm 6.1)$

AK070854 $219.3( \pm 50.5)$

$\begin{array}{ll}\text { AK059281 N. D.* } \\ \text { AK069225 } & \text { N. D.* }\end{array}$

AK071735 $40.8( \pm 17.7)$

AK069788 $50.2( \pm 15.9)$

AK108727 $47.3( \pm 5.2)$

AK071735 $27.1( \pm 10.9)$

AK072672 $19.5( \pm 7.2)$

$$
\text { N. D.* }
$$

AK069852 $242.3( \pm 65)$

AK070064 $63.7( \pm 17.4)$

AK071248 $32.1( \pm 14.8)$

AK120999 $25.3( \pm 9.7)$

AK058325 $608.9( \pm 121.1)$

AK100437 $30.4( \pm 10.5)$

AK071790 $21.4( \pm 9.1)$

AK069605 $32.2( \pm 5.4)$

AK107936 $99.1( \pm 36.6)$

AK106951 $19.3( \pm 5.2)$

AK066396 $390.5( \pm 134.8)$

AK100654 $19.1( \pm 3.3)$

AK120862 $12.5( \pm 4)$

AK119707 N. D.*

AK072945 $16.2( \pm 2.3)$

AK072520 $318.9( \pm 90.6)$

$16.4( \pm 4.2)$

$\begin{array}{ll}\text { AK100522 } & 28.2( \pm 7.8)\end{array}$

AK121194 $22.8( \pm 4.6$

$25.3( \pm 4.9)$

AK100785 $53.5( \pm 16.9)$

$37.6( \pm 2.8)$

AK069047 $17.0( \pm 5.0)$

AK066596 $60.6( \pm 15.9)$

AK065130 $23.7( \pm 6.8)$

AK068410 $118.3( \pm 47.8)$

$26.3( \pm 7.8)$

AK061782 $89.9(+17.6)$

$89.9( \pm 17.6)$
$31.3( \pm 10.7)$

AK058850 $10.7( \pm 2.9)$

AK064886 $57.6( \pm 24.1)$

AK065832 $29.6( \pm 18.8)$

AK101996 $17.8( \pm 5.6)$

AK106886 $8.5( \pm 5.3)$

AK072748 $58.5( \pm 13.1)$

AK066721 $36.8( \pm 9.2)$

$72 \quad( \pm 20.7)$

$\begin{array}{cc}- & 25.8( \pm 18.8) \\ \text { AK121392 } & 20.0( \pm 5.2)\end{array}$

AK100163 $40.5( \pm 15.8)$

AK071282 N. D.*

AK120862 N. D**

AK106977 $44.4( \pm 36)$

$59.2( \pm 15.6)$

AK099272 $\quad 99.0( \pm 15.7)$
$33.7( \pm 12.3) \quad 3402.0( \pm 2204.5) \quad 35.2( \pm 15)$

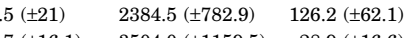

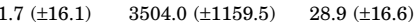

$105.0( \pm 110.1)$

$3504.0( \pm 1159.5$

$139.3( \pm 128.0)$

$400.2( \pm 94.5)$

$20.9( \pm 8.4)$

$9.6( \pm 11.2)$

$18.0( \pm 4.0)$

$76.5( \pm 18.7)$

$147.8( \pm 33.1)$

$6.9( \pm 2.7)$

7.1 \pm 11.7

$36.7( \pm 22.4)$

$282 \quad( \pm 60.1)$

$138.8( \pm 51.7)$

$18.5( \pm 5)$

$58.8( \pm 10.1)$

$98.4( \pm 20.8)$

$21.9( \pm 6.5)$

$41.4( \pm 11.4)$

$46.9(+8)$

$49.6( \pm 9.8)$

$13.8( \pm 7.2)$

$148.4( \pm 51.7)$

$37.5( \pm 4.8)$

$128.1( \pm 27)$

$68.7( \pm 16.3)$

$15.4( \pm 3.1)$

$26.4(+10)$

$32.7( \pm 11.3)$

$35.8( \pm 10.4)$

$22.1( \pm 5.1)$

( \pm 8.6$)$

N. D.*

$302.3( \pm 88.2)$

$71.6( \pm 14.5)$

$38.3( \pm 8.3)$

$21.0( \pm 10.1)$

$274.8( \pm 57.3)$

$37.4( \pm 8.6)$

$( \pm 3.8)$

$235( \pm 8.4)$

$62.2( \pm 24.5)$

$15.7( \pm 3.4)$

$248.6( \pm 97.4)$

$18.6( \pm 5.5)$

$15.8( \pm 5.7)$

$18.2( \pm 10.1)$

$9.7( \pm 1.9)$

$194.6( \pm 35.2)$

$9.2( \pm 2.3)$

$25.9( \pm 11)$

$60.7( \pm 12.5)$

$16.2( \pm 2.9)$

$44.2( \pm 18.5)$

$17.4( \pm 5)$

$14.5( \pm 6.3)$

$62.2( \pm 14.3)$

$16.9( \pm 3.9)$

$68.3( \pm 28.2)$

$20.2( \pm 5.9)$

$73.1( \pm 19.2)$

$21.6( \pm 3.5)$

$10.4( \pm 7.1)$

$34 \quad( \pm 30.2)$

$33.1( \pm 21.8)$

$12.8( \pm 13.4)$

$4.1( \pm 1.9)$

$93.0( \pm 56.4)$
$36.9( \pm 23.3)$

$34.2( \pm 6.2)$

$19.3( \pm 6.1)$

$13.0( \pm 4.2)$

$17.1( \pm 12.2)$

$10.4( \pm 6.2)$

$33.3( \pm 25.4)$

$16.2( \pm 10.5)$

$43.4( \pm 14.3)$

$112.0( \pm 36.3)$

$4.6( \pm 5.7)$ $\begin{array}{ll}295.9( \pm 102.8) & 35.4( \pm 24.8) \\ 39.36 .1)\end{array}$

$( \pm 312.5)$

$3666.0( \pm 562.9)$

$3453.0( \pm 731.9)$

$33.5( \pm 96.6)$

$205.2( \pm 84.9)$

$5.1( \pm 0.7)$

$32.3( \pm 21)$

$19.2( \pm 11.5)$

211.5

$3920 \quad( \pm 1170.8)$
$2328.0( \pm 233.9)$

$296.0(+466.0)$

$509.9( \pm 147.7)$

$775.8( \pm 205.9)$

$1512.0( \pm 268.1)$

$1336.0( \pm 159.9)$

$3868.0( \pm 535)$

$646.4( \pm 146.1)$

$1560.0( \pm 374.6)$

$2958.0( \pm 666.9)$

$1715.0( \pm 461.9)$

$1064.0( \pm 189.5)$

$498.0( \pm 106.8)$

$160.1( \pm 31.5)$

$748.6( \pm 354.3)$

$585.9( \pm 232.5)$

$519.1( \pm 110)$

$542.8( \pm 182.8)$

$1538.0( \pm 462.0)$

$574.3(+139.0)$

$2273.0( \pm 708.3)$

$547.3( \pm 146)$

$1182.0( \pm 258.0)$

$2047.0( \pm 525.7)$

$3212.0( \pm 622.0)$

$2306.0( \pm 420.0)$

$1176.0( \pm 410.2)$

$989.6( \pm 333.2)$

$1709 \quad( \pm 559)$

$4012.0( \pm 1121.9)$

$4053.0( \pm 962.3)$

$483.5( \pm 113.9)$

$1274.0( \pm 327.6)$

$581.0( \pm 171.7)$

$296.6( \pm 62.7)$

$4431.0( \pm 781.9)$

$75.6( \pm 26.4)$

$371.7( \pm 98.3)$

$1206.0( \pm 238.0)$

$226.3( \pm 56.2)$

$2386 \quad( \pm 453.9)$

$3000 \quad( \pm 1003.5)$

$273.5( \pm 67)$

$1561 \quad( \pm 247.1)$

$435.8( \pm 109.4)$

$7501.0( \pm 1482)$

$5084.0( \pm 392.6)$

$3459.0( \pm 500.6)$

$3627.0( \pm 426.9)$

$428.5( \pm 129.1)$

$0370.0( \pm 3505.3)$

$553.5( \pm 123.4)$

$1599.0( \pm 289.4)$

$2500.0( \pm 536.9)$

$9140.0( \pm 1205.9)$

$6300.0( \pm 797.1)$

$154.2( \pm 44.1)$

$593.3( \pm 66.2)$

$297.3( \pm 80.5)$

$1176.0( \pm 415.2)$

$3887.0( \pm 1030.7)$

$687.1( \pm 190.6)$

$781.6( \pm 175)$

$5115.0( \pm 1070.9)$
$1216.0( \pm 884.8)$

$122.3( \pm 54.9) \quad 118$

$30.7( \pm 20.1)$

$21.2( \pm 11.0)$

$133.4( \pm 50.1)$

$20.7( \pm 13.7)$

$25.0(+16.4)$

$8 \quad( \pm 37)$

$14.5( \pm 8.0)$

$21.2( \pm 2.2)$

$32.3( \pm 15.6)$

$84.1(+22)$

$45.1( \pm 19.8)$

$20.6( \pm 8.7)$

$57.3( \pm 19.1)$

$22.3( \pm 9.6)$

$163.4( \pm 72$

$29.5( \pm 4.7)$

$59.2( \pm 21.2) \quad 4 \quad 8.9( \pm 24.4) \quad 82.6( \pm 16.3) \quad 40.4( \pm 27.8)$

$103.0( \pm 128.4) \quad$ N. D.* $\quad 106.2( \pm 32.2) \quad 77.6( \pm 197.6)$ $324 \quad( \pm 122.1) \quad 237.8( \pm 94.1) \quad 330.7( \pm 85.4) \quad 385.0( \pm 214.9)$

$\begin{array}{lllll} & 132( \pm 7) & 67.7( \pm 26.7) & 24.3( \pm 21.1)\end{array}$

$93.5( \pm 21.2) \quad 75.1( \pm 30.1) \quad 110.9( \pm 9.8) \quad 47.8( \pm 34.1)$

$\begin{array}{llll}73.0( \pm 30.4) & \text { N. D.** } & 116.9( \pm 20.2) & 16.1( \pm 26.9)\end{array}$

$34.4( \pm 41.9) \quad 14.9( \pm 7.2) \quad 21.3( \pm 7.6) \quad 19.1( \pm 76.4)$

$20.1( \pm 10.7) \quad$ N. D.* $\quad 59.0( \pm 16.1) \quad 19.0( \pm 15.4)$

$37.3(+16.4) \quad 30.4(+16) \quad 68.7(+35.4) \quad 54.9(+29.6)$

$55.5( \pm 11.5) \quad 50.1( \pm 20.6) \quad 59.4( \pm 25.1) \quad 93.8( \pm 33.1)$

$28.7( \pm 23.9) \quad 14.3( \pm 16.2) \quad 53.2( \pm 16.4) \quad 65.2( \pm 49.9)$

$32.6( \pm 26.6) \quad 24.8( \pm 12) \quad 90.4( \pm 31.9) \quad 25.0( \pm 21.6)$

$19.3(+9.1) \quad$ N. D* $\quad$ N. D* $\quad 3.2(+11.0)$

$111.7( \pm 42.5) \quad 130.6( \pm 36.3) \quad 220.0( \pm 65.1) \quad 149.9( \pm 59.7)$

$50.9( \pm 11.9) \quad 44.4( \pm 14.6) \quad 88.4( \pm 70.4) \quad 110.3( \pm 55.4)$

$\begin{array}{llll}\text { N. D.* } & 26.2( \pm 8.3) & 83.8( \pm 25.1) & 41.1( \pm 41.1)\end{array}$ $\begin{array}{lllll}18 & ( \pm 5.6) & 31.3(+24.5) & 124.5(+16.8) & 95.5( \pm 57.2)\end{array}$

$337 \quad( \pm 128.5) \quad 342.6( \pm 120.2) \quad 568.4( \pm 123.3) \quad 121.6( \pm 55.4)$

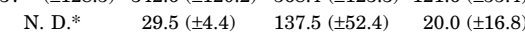

$44.9( \pm 56.3) \quad 25.6( \pm 16.7) \quad 70.2( \pm 32.5) \quad 58.2( \pm 81.7)$

$48.4( \pm 23.6) \quad 36.5( \pm 10) \quad 78.4( \pm 27.6) \quad 126.8( \pm 63.3)$

$114.1( \pm 35.5) \quad 82.6( \pm 33) \quad 103.6( \pm 48.2) \quad 189.6( \pm 107.7)$

$19.1( \pm 9.8) \quad 18.7( \pm 13.4) \quad 212.5( \pm 99.4) \quad 20.8( \pm 16.2)$

$\begin{array}{lll} & & \end{array} 2.1( \pm 195.8) \quad 357.9( \pm 188.1) \quad 584.7( \pm 157) \quad 346.1( \pm 248.2)$

$17.1 \pm 55) \quad 50.7( \pm 42.5) \quad$ N. D.* $\quad 19.6( \pm 67.1)$

$12 \quad( \pm 5.2) \quad 14.8( \pm 6.1) \quad 136.2( \pm 93) \quad 6.7( \pm 13)$

$20.7( \pm 7.9) \quad 12.2( \pm 11.1) \quad 112.0( \pm 29.5) \quad 14.1( \pm 19.2)$

$19.9( \pm 9.2) \quad 10.1( \pm 7.2) \quad 23.9( \pm 10.7) \quad 19.7( \pm 42.4)$

$525.7( \pm 216) \quad 453.1( \pm 153.4) \quad 498.4( \pm 115.9) \quad 605.9( \pm 271.7)$

$8.0( \pm 3.6)$

$\begin{array}{llr}\text { N. D.* } & 53.6( \pm 17.7) & 1.0( \pm 0.2) \\ & ( \pm 13.8\end{array}$

$22.5( \pm 14.1) \quad 104.2( \pm 23.2) \quad 15.3( \pm 19.8)$

$26.4(+13.9) \quad$ N. D* $25.8( \pm 23.3)$

$78.2( \pm 38.3) \quad 211.5( \pm 54.2) \quad 105.4( \pm 40.2)$ 
were handled as independent groups hereafter.

Hierarchical Clustering of cDNA expressed abundantly in anthers tissues In order to identify cDNA clones specifically expressed in anther tissues, and to detect the cDNA clones which were co-regulated according to the developmental stage in anther tissues, cluster analysis of highly expressed clones in anther tissues (396 clones; anther/leaves>6.0) was performed. For construction of a hierarchical cluster tree, we used the signal data averaged for each stage of the samples (A1 to A3, P1 to $\mathrm{P} 3$, and RL), instead of the Cy5 (signal from reproductive tissues)/Cy3 (signal from leaf tissues) ratio for the purpose of identifying anther-specific genes that are not expressed or are expressed at an extremely low level in other tissues, pistil and leaf.

Four distinct patterns was observed from the clustering analysis (Fig. 2). Thirty-four cDNA clones (23 groups) that were highly expressed in A1 were clustered into Cluster RA1. Cluster RA2 included 56 cDNA clones (28 groups) that were mainly expressed in A2. Cluster RA1/ 2 included 32 cDNA clones (16 groups) that were highly expressed in A1 and A2. Cluster RA3 included 132 cDNA clones (89 groups) that were highly expressed in A3, and were slightly expressed in other stages and organs (Table 2). According to the gain of the developmental stage in anther tissues, a larger number of specific genes were observed. A similar trend was observed in the anther transcriptome analysis of different plant species L. japonicus and A. thaliana (Endo et al., 2002; Amagai et al. 2003).

To identify and characterize the putative function of specific genes, which were classified into the Cluster RA1, RA1/2, RA2 and RA3, a homology search was performed (see Materials and Methods). About half of the antherspecific genes, which were classified into three clusters (Cluster RA1, RA1/2, and RA2), could be deduced by their functions from the homology search. In the case of the Cluster RA3, approximately $70 \%$ of the specific genes could be estimated their putative functions from the homology search. In contrast, the remaining specific genes in each cluster could not be determined by their function. These results are shown in Table 2. Furthermore, the expression data and the sequence similarity, which were based on the full-length cDNA description or BLASTX homology search of cDNA clones, are shown in Table 3.

The reliability for our array experiment was confirmed by two independent viewpoints. One was owing to the strategy of microarray analysis. As described above, our rice microarray was constructed from randomly picked-up clones. After hybridization experiments, we found duplicated clones from the sequence similarity. These duplicated clones, which were scattered on the microarray glass slide showed quite similar expression profiles. The other point was that several clones identical to the genes, which had been already characterized as anther- and/or pollen-specific, were identified in several clusters (Tsuchiya et al. 1992; Tsuchiya et al. 1994; Hihara et al. 1996; Wang et al. 2003; Li et al. 2003; Kim et al. 1993; Huang et al. 1996; Albani et al. 1992; Niogret et al. 1991; Table 3).

As shown in Table 3, Cluster RA3 included several genes, which had already been reported to be pollen-specific genes, and these genes are known to play an important role in pollen germination or pollen tube growth (Taylor and Hepler 1997). In the case of the model legume $L$. japonicus, the majority of genes specifically expressed in the mature anther tissues on the microarray analysis was specifically expressed in the mature pollen grains (H. Masuko, M. Endo and M. Watanabe, unpublished data). These data indicate that most genes classified into Cluster RA3 should be expressed in mature pollen grains and function in pollen germination pollen tube growth.

Spatial expression pattern of genes expressed specifically in immature anther tissues The anther contains a number of specialized cells and tissues, and many physiological events occur during anther development as described above. We identified several cDNA clones, which were expressed specifically or predominantly in immature anther tissues using cDNA microarray in this experiment. To determine more precisely spatial and temporal patterns of the groups of 11,8 and $3 \mathrm{cDNA}$ clones, which were classified into Cluster RA1, RA1/2, and Cluster RA2, respectively, we performed RNA in situ hybridization with transverse section of flowers in stages 1,2 and 3. In the RNA in situ hybridization experiments, the entire cDNA fragment, which was inserted into the plasmid vector, was used to prepare the sense and antisense RNA probes. Representative data of RNA in situ hybridization are shown in Fig. 3, and the results of in situ hybridization are summarized in Table 4. The results of the temporal expression pattern obtained by in situ hybridization were in agreement with those obtained by DNA microarray analysis in twenty-one cDNA groups that we examined. Furthermore, when compared the pattern of the hybridization signal among each stage, it was clearly different among each stage, indicating that the different sets of genes should be expressed in each developmental stage of anther tissues.

Genes specifically expressed in the anther tapetum In twenty-three groups of cDNA clones, which we examined, the hybridization signal of 17 groups of cDNA clones was strictly restricted to the anther tapetum. Furthermore, based on their pattern of temporal expression in the tapetum, we could classify $17 \mathrm{cDNA}$ groups into three distinct classes. 
(A)

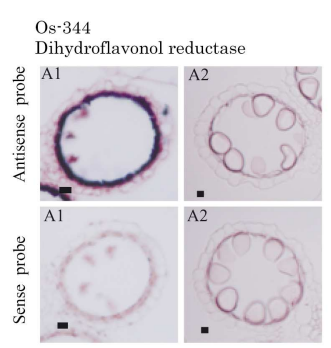

(B)

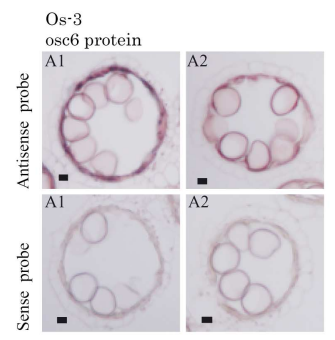

(C)

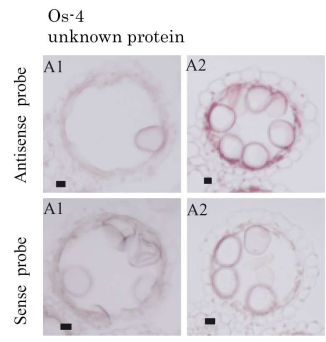

(D)

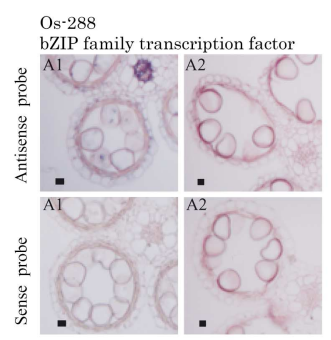

$$
\text { Os-56 }
$$

Os-56
unknown protein

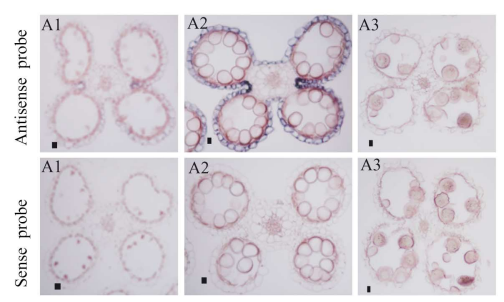

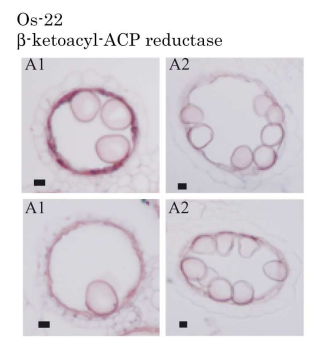
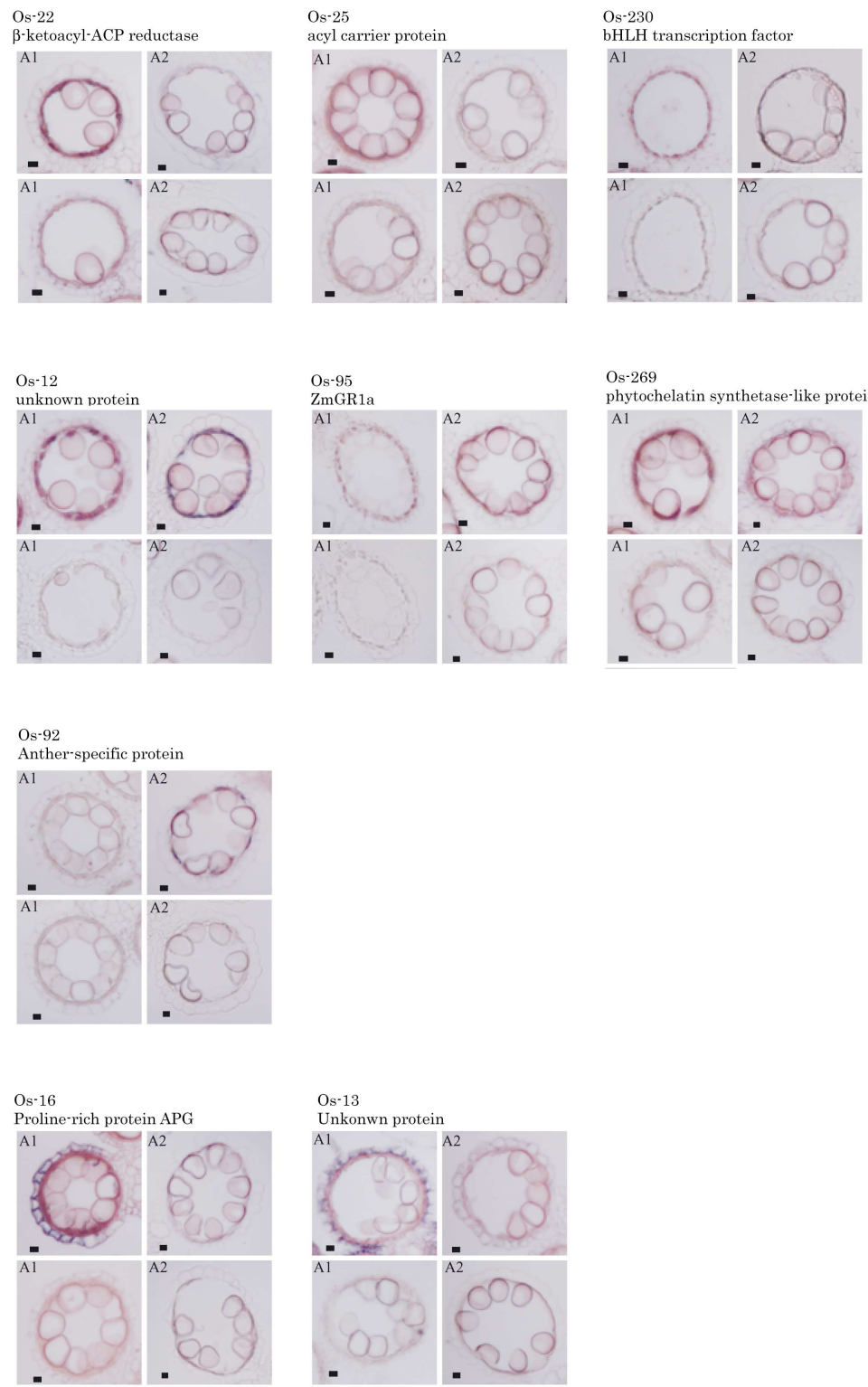

Os-269

phytochelatin synthetase-like protein
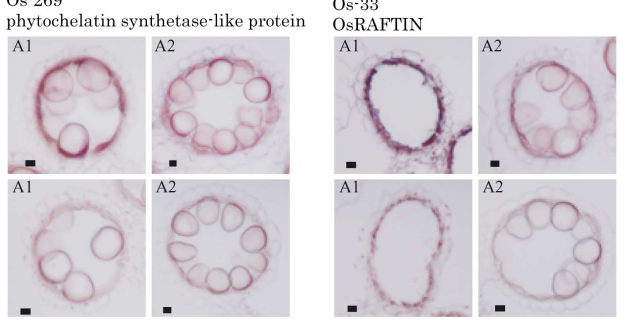

Os-262

similar to mammalian MHC III region
protein G9a

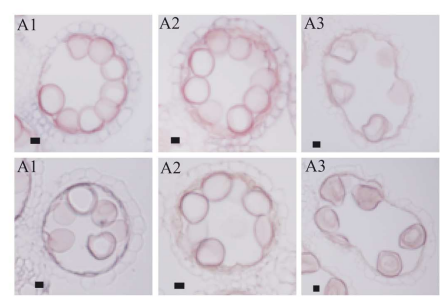

Os-6

Proline-rich protein

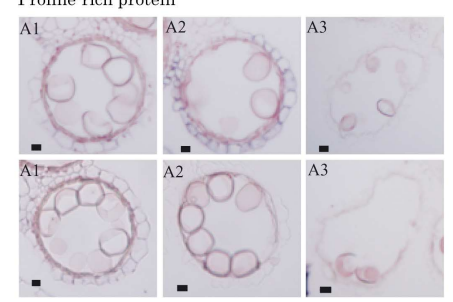

Fig. 3. In situ localization of anther-specific transcripts during anther development. Dig-labeled antisense and sense (control) RNA probes were hybridized to the cross-section of the anther tissues at different developmental stages of rice. Cross-section of the anther locules or anther at different development stages are shown in Fig. 1. Anther-specific genes were classified with their special and temporal expression patterns. Cross-section of the anther locule at stages 1 and 2 are shown. (A) Genes specifically expressed in the tapetum at stage 1. (B) Genes specifically expressed in the tapetum at stages 1 and 2. (C) Genes specifically expressed in the tapetum at stage 2. (D) Genes expressed in the anther tissues except tapetum. Bar $=10 \mu \mathrm{m}$. 
Table 4. Results of RNA in situ hybridization in rice flower buds.

\begin{tabular}{|c|c|c|c|c|}
\hline Group $^{a}$ & Cluster & Functional definition $^{\mathrm{b}}$ & Accession $^{c}$ & Expression pattern \\
\hline Os-8 & Cluster RA1 & SFFV env & AK058203 & tapetum at the stage 1 \\
\hline Os-14 & Cluster RA1 & Osc4 protein & AK064717 & tapetum at the stage 1 \\
\hline Os-22 & Cluster RA1 & $\beta$-ketoacyl-ACP reductase & AK109188 & tapetum at the stage 1 \\
\hline Os-25 & Cluster RA1 & Acyl carrier protein II & AK058903 & tapetum at the stage 1 \\
\hline Os-40 & Cluster RA1 & Unknown protein (CAD37124.3) & - & tapetum at the stage 1 \\
\hline Os-87 & Cluster RA1 & YY1 protein & AK107918 & tapetum at the stage 1 \\
\hline Os-99 & Cluster RA1 & Unknown protein & AK069589 & tapetum at the stage 1 \\
\hline Os-230 & Cluster RA1 & bHLH transcription factor & AK106761 & tapetum at the stage 1 \\
\hline Os-335 & Cluster RA1 & Unknown protein & AK106780 & tapetum at the stage 1 \\
\hline Os-344 & Cluster RA1 & Dihydroflavonol reductase & AK099770 & tapetum at the stage 1 \\
\hline Os-3 & Cluster RA1/2 & Osc6 protein & AK064672 & tapetum at the stage 1 and 2 \\
\hline Os-12 & Cluster RA2 & Unknown protein & AK070921 & tapetum at the stage 1 and 2 \\
\hline Os-33 & Cluster RA1/2 & OsRAFTIN & AK120942 & tapetum at the stage 1 and 2 \\
\hline Os-95 & Cluster RA1/2 & Proline-rich protein & AK058218 & tapetum at the stage 1 and 2 \\
\hline Os-269 & Cluster RA1/2 & Phytochelatin synthetase-like protein & AK070472 & tapetum at the stage 1 and 2 \\
\hline Os-4 & Cluster RA2 & Unknown protein & AK069454 & tapetum at the stage 2 \\
\hline Os-92 & Cluster RA2 & Anther-specific protein & AK070978 & tapetum at the stage 2 \\
\hline Os-56 & Cluster RA1/2 & Unknown protein (AAP21417.1) & - & stomium at the stage 1 and 2 \\
\hline Os-16 & Cluster RA1/2 & Proline-rich protein APG & AK106778 & anther wall and tapetum at the stage 1 \\
\hline Os-262 & Cluster RA1/2 & Mammalian MHC III region protein G9a & AK067187 & epidermis at the stage 1 and 2 \\
\hline Os-13 & Cluster RA1/2 & Unknown protein & AK062834 & epidermis at the stage 1 and 2 \\
\hline Os-6 & Cluster RA2 & Proline-rich protein & AK059665 & epidermis at the stage 2 \\
\hline Os-288 & Cluster RA1 & Unknown protein & AK072267 & filament and epidermis at the stage 1 \\
\hline
\end{tabular}

${ }^{\mathrm{a}}$ Group consisted of cDNA clones which have over lap sequence over 95\% identity for more than 100bp (See Results and Disucssion).

${ }^{\mathrm{b}}$ Gene with functional annotation obtained from KOME full length rice cDNA database. When cDNA was not identical full length rice cDNA, accession number which obtained from BLASTX search against against nr, non-redundant protein database in DDBJ (http://ddbj.nig.ac.jp) are given behind the putative gene identities.

${ }^{\mathrm{c}}$ Acssesion number of full length cDNA identical to spotted cDNA.

In the case of Class I, ten groups of cDNA clones were specifically or predominantly expressed in the tapetum at stage 1 before the degeneration of the tapetum occurred. As described above, two groups of cDNA clones (Os-14 and $O s-87$ ), which corresponded to the known tapetumspecific genes, YY1 (Hihara et al. 1996) and Osc4 (Tsuchiya et al. 1994), respectively, were specifically expressed in stage 1 tapetum (data not shown). The temporal and spatial expression patterns of these clones in tapetum cells corresponded to those of $Y Y 1$ and Osc4 genes in the previous reports (Hihara et al. 1996; Tsuchiya et al. 1994), though the function of these genes in tapetum could not be estimated from the nucleotide sequence similarity.

Tapetal cells play an essential role in the production of protein, lipids and flavonol that are secreted into pollen sac and form part of the pollen grain outer wall (Goldberg et al. 1993). Previous studies have shown that several genes involved in secondary metabolism were specifically or predominantly expressed in the tapetum (Vauterin et al. 1999; Piffanelli et al. 1997; Kaneko et al. 2003). In this Class I, we found one group of cDNA clones (Os-334), which were involved in the production of a different type of secondary metabolites, anthocyanin, in this experiment (Fig. 3A). Os-334 showed sequence similarity to gene encoding dihydroflavonol reductase (DFR) which catalyzed the conversion of dihydroflavonol into leucoanthocyanidin in the anthocyanin biosynthesis pathway (Deboo et al., 1995). To date, genes encoding key enzymes of the flavonoid biosynthesis pathway, phenylalanine ammonia lyase (PAL) and chalcone synthase (CHS), have been reported to be specifically expressed in the tapetum (Shen and Hsu 1992; Hihara et al. 1996). In the disrupted tobacco plants of these two genes (PAL and $C H S)$ by tapetum-specific promoter, a decrease of pollen fertility was observed (Matsuda et al. 1996; Matsuda et al. 1997). Furthermore, flavonols, which were produced from dihydroflavonol by flavonol synthase, were required for func- 
tional pollen grains (Deboo et al. 1995). However, it was reported that anthocyanins are not always essential pigment for functional pollen grains in maize (Deboo et al. 1995). Thus, the role of genes related to anthocyanin biosynthesis pathway, which were found in this experiment, could not be assumed during anther and/or pollen development in rice.

Os-22 and Os-25, which showed sequence similarity with $\beta$-ketoacyl-ACP reductase and acyl carrier protein (ACP), respectively, also were specifically expressed in stage 1 tapetum (Fig. 3A), and were key enzymes of the fatty acid biosynthesis pathway (Millar et al. 2000). Fatty acids are thought to be a precursor of exine and pollen coat, which covers the pollen surface and are secreted from the tapetum into the anther locule (Piffanelli et al. 1998). In the case of one of the cruciferous plants, $B$. napus, the other two genes encoding enoyl-ACP reductase (EAR) and stearoyl-ACP desaturase (SAD), which were also key enzymes of fatty acid biosynthesis, were specifically expressed in the tapetum as well as the unicellular microspores, indicating that fatty acid biosynthesis was needed to supply intracellular lipid body in the pollen grains (Piffanelli et al. 1997). In our in situ analysis, both $O s-22$ and $O s-25$ were specifically expressed in anther tapetum at stage 1 , and no hybridization signal was observed in pollen at any developmental stages (Fig. $3 \mathrm{~A})$. The difference of gene expression in pollen would be owing to the difference of plant species or enzymes. Nevertheless, a series of genes encoding key enzymes of fatty acid biosynthesis should be important for functional tapetum cells, which provide metabolites relevant to fatty acids to pollen surfaces (Piffanelli et al. 1998).

Furthermore, we found cDNA clones $(\mathrm{Os}-230)$ which were highly homologous to a gene encoding Arabidopsis MYC bHLH transcription factor, AMS, in Class I (Fig. 3A, Table 4). In the ams mutant of Arabidopsis, irregular development of tapetum was reported, indicating that this $A M S$ gene has an important function in anther tapetum development (Sorensen et al., 2003). Both genes $(O s-230$ and $A M S$ ) were specifically expressed in tapetum of stage 1. Taking together the sequence similarity and expression pattern, Os-230 might be an orthologous gene to $A M S$ of Arabidopsis, and should regulate the expression of several genes, which functioned before degradation of tapetum.

Spatially and temporally co-regulated genes in Class I, whose annotations were different from each other, should co-operatively function in the development of anther tapetum in rice. These genes should especially function in providing several metabolites from anther tapetum to pollen surfaces.

In the case of Class II, cDNA clones, which were classified into five groups, were specifically and/or predominantly expressed in the anther tapetum at stage 1 and 2 (Fig. 3B, Table 4). The degradation of anther tapetum was observed during stage 1 and stage 2 .

We found two known rice tapetum-specific genes in this Class II. One was Os-33 encoding osRAFTIN, and the other was Os-3 encoding Osc6 (Fig. 3B, Table 4). Our RNA in situ hybridization data of these genes showed quite a similar expression pattern to that described in previous reports (Wang et al. 2003; Tsuchiya et al. 1994).

$O s$-95 showed a sequence similarity to ZmGR1a/b, which has been characterized as a "gibberellins (GAs) responsible gene" in maize (Ogawa et al. 1999) was contained in Class II (Fig. 3, Table 3). It has been suggested that anther tissues are important for the source of GAs (Weiss et al. 1995). In addition, it has been shown that the expression of the genes related to GAs-biosynthesis is restricted to the anther tapetum in rice (Kaneko et al. 2003). Taking these results together, Os-95 might function in the downstream of GAs signaling cascade within the anther tapetum, though the precise function could not be determined in this experiment.

Because Class II included Os-33 (osRAFTIN) that provides its protein into microspores (Wang et al. 2003), genes in Class II should also play important roles in the secretion of proteins and/or other metabolites from anther tapetum to the pollen surface similar to the Class I genes as described above.

To date, a number of genes, which have been specifically expressed in anther tapetum at stage 1 have been isolated and characterized (Koltunow et al. 1990; Jeon et al. 1999; Rubinelli et al. 1998; Tsuchiya et al. 1994; Hihara et al. 1996; Kapoor et al. 2002). However, no genes, which are specifically expressed in the tapetum after starting of the degradation have been identified. In the case of Class III, cDNA clones, which were classified into two groups (Os-4; unknown gene, Os-92; anther-specific gene), were specifically and/or predominantly expressed in the anther tapetum at stage 2 (Fig. 3C). The degradation of the tapetum started or occurred during stage 2. This type of expression pattern in the anther tapetum is novel. However, we could not estimate the roles of clones in Class III from the annotation in this experiment. As the expression of all of the clones in Class III were restricted in anther tapetum at stage 2, the function of these clones should be related to the degradation of anther tapetum.

Genes specifically expressed in the anther tissues except tapetum As described above, the hybridization signals in most of the clones characterized in this study were specifically localized in the anther tapetum. However, other cells of anther tissues except tapetum are also important for functional roles in the anther. In fact, morphological alteration was observed in the epidermal cells. During stages 1 and 2, the epidermal cells gradually expanded and degenerated for anther dehiscence during stages 2 and 3 (Fig. 1). In this experiment, we found 
six groups of cDNA clones, which were expressed in the epidermis and other tissues of the anther (Fig. 3D). The temporal and spatial expression patterns of these cDNA clones were distinct from those of known anther-specific genes.

In the case of $O s-56$, which did not show any significant similarity to known genes, the hybridization signals were observed in the epidermal cells at stages 1 and 2 (Fig. $3 \mathrm{D})$. Strong signals were especially observed in the stomium cells, whose function was linkage of two neighboring locules and breakdown at dehiscence. However, at stage 3, no signals were detected in any parts of anther tissues. To date, several genes, which were specifically expressed in the epidermal or stomium cells were identified and characterized (Evard et al. 1991; Ge et al. 2000). The transcripts of the $S F 2, S F 18$, and $S F 19$ in sunflower were observed in the epidermis (Evard et al. 1991). In the case of NEC1 in Petunia hybrida, GUS activity under control of NEC1 promoter was detected in the stomium cells (Ge et al. 2000). Furthermore, the timing of expression of any of these genes was at the mature stage of anther tissues (Evard et al. 1991; Ge et al. 2000). In the disrupted lines of NEC1, an "early open anther" phenotype was observed, indicating that NEC1 might be involved in the development of stomium cells (Ge et al. 2001). In contrast, the transcript of $O s-56$ was restricted in the epidermal and stomium cells in immature anther at stages 1 and 2, as described above. Combining these results, the potential roles of Os-56 might be involved in establishment of the functional stomium cell and epidermal cells, or may be related to cell expansion at the immature stage of anther tissues.

Os-6 showed sequence similarity to genes encoding proline-rich proteins (PRPs) in other plant species. At stage 2 , in which the expansion of epidermal cells was observed, the hybridization signals of $O s-6$ were detected in the epidermal cells (Fig. 3D). PRPs are thought to contribute to the cell wall structure of specific cell types based both on their expression patterns during plant development and their ability to associate with cross-link components within the cell wall (Showalter, 1993). Taking these results together, $O s-6$ might function in the cell wall matrix of the expanding epidermal cells in the anther tissues.

In the case of $O s-288$, the nucleotide sequence of the clones showed similarity to that of bZIP type transcription factors. Interestingly, the hybridization signals of the clones were specifically observed in the filaments and epidermis at stage 1 (Fig. 3D). According to the maturation of anther tissues, the quick elongation of the filament was observed. Therefore, $O s$ - 288 might be related to the regulation of elongation of the filament.

\section{CONCULSION}

In this study, we performed cDNA microarray and in situ hybridization analyses to monitor gene expression patterns during anther development in rice. The analysis of microarray, which was fabricated with 4,304 cDNA clones, revealed that several genes were co-regulated with the developmentally stage-specific manners of the anther tissues in four distinct clusters, indicating that genes expressed in anther tissues were controlled by several different programs, which were partitioned with respect to both cell types and developmental types (Koltunow et al. 1990). From the analyses of microarray and RNA in situ hybridization, we found novel tapetum-specific genes at stage 2 where the degradation of the tapetum occurred. To the best of our knowledge, it is important for identification of tissue-specific genes to construct the custom-array, whose clones are derived from cDNA library of its tissue.

In this experiment, about $30 \%$ to $50 \%$ of anther-specific genes were novel in each cluster. To date, the draft sequence of rice has been determined (Goff et al. 2002; Yu et al. 2002). Combining sequence data and the gene disruption techniques, RNAi, antisense, etc., novel genes should be able to be functionally characterized, which should allow us to learn new aspects about the mechanisms of anther development.

This work was supported in part by a grant from the Ministry of Agriculture, Forestry and Fisheries of Japan (Rice Genome Project MA-2208 and MA-2211) to T. T. and M. W., respectively, and from the Ministry of Education, Sports, Science, and Technology of Japan (Grant-in-Aid for the 21st Century COE Program to Iwate University) to M. W. M. E. is a recipient of Research Fellowships of the Japan Society for the Promotion of Science for Young Scientists. We thank Dr. Hiroyuki Hirano (The University of Tokyo) for providing technical advice in analyzing array data. We also thank Dr. Toshihiko Hayakawa (Tohoku University) and Dr. Keiki Ishiyama (RIKEN) for providing technical advice about in situ hybridization. The authors are also grateful to Miss Ayako Chiba, Miss Yukiko Ohyama and Mr. Hiroyuki Ishikawa (Iwate University) for their technical assistance.

\section{REFERENCES}

Albani, D., Sardana, R., Robert, L. S., Altosaar, I., Arnison, P. G., and Fabijanski, S. F. (1992) A Brassica napus gene family which shows sequence similarity to ascorbate oxidase is expressed in developing pollen. Molecular characterization and analysis of promoter activity in transgenic tobacco plants. Plant J. 2, 331-342.

Altschul, S. F., Gish, W., Miller, W., Myers, E. W., and Lipman, D. J. (1990) Basic local alignment search tool. J. Mol. Biol. 215, 403-410.

Amagai, M., Ariizumi, T., Endo, M., Hatakeyama, K., Kuwata, C., Shibata, D., Toriyama, K., and Watanabe, M. (2003) Identification of anther-specific genes in a cruciferous model plant, Arabidopsis thaliana, by using a combination of Arabidopsis macroarray and mRNA derived from Brassica 
oleracea. Sex. Plant Reprod. 15, 213-220.

Bathurst, N. O. (1954) The amino-acids of grass pollen. J. Exp. Bot. 5, 253-256.

Becker, J. D., Boavida, L. C., Carneiro, J., Haury. M., and Feijo, J. A. (2003) Transcriptional profiling of Arabidopsis tissues reveals the unique characteristics of the pollen transcriptome. Plant Physiol. 133, 713-725.

Deboo, G. B., Albertsen, M. C., and Taylor, L. P. (1995) Flavanone 3-hydroxylase transcripts and flavonol accumulation are temporally coordinate in maize anthers. Plant J. 7, 703-713.

Delauney, A. J., and Verma, D. P. S. (1993) Proline biosynthesis and osmoregulation in plants. Plant J. 4, 215-223.

Eisen, M. B., Spellman, P. T., Brown, P. O. and Bostein, D. (1998) Cluster analysis and display of genome-wide expression patterns. Proc. Natl. Acad. Sci. USA 95, 14863-14868.

Endo, M., Kokubun, T., Takahata, Y., Higashitani, A., Tabata, S., and Watanabe, M. (2000) Analysis of expressed sequence tags of flower buds in Lotus japonicus. DNA Res. 7, 213-216.

Endo, M., Matsubara, Kokubun, T., Masuko, H., Takahata, Y., Tsuchiya, T., Fukuda, H., Demura, T., and Watanabe, M. (2002) The advantages of cDNA microarray as an effective tool for identification of reproductive organ-specific genes in a model legume, Lotus japonicus. FEBS Lett. 514, 229-237.

Evrard, J. L., Jako, C., Saint-Guily, A., Weil, J. H., and Kuntz, M. (1991) Anther-specific, developmentally regulated expression of genes encoding a new class of proline-rich proteins in sunflower. Plant Mol. Biol. 16, 271-281.

Fujii, N., Kamada, M., Yamasaki, S., and Takahashi, H. (2000) Differential accumulation of Aux/IAA mRNA during seedling development and gravity response in cucumber (Cucumis sativas L.). Plant Mol. Biol. 42, 731-740.

Fujita, T., Maggio, A., Garcia-Rios, M., Bressan, R. A., and Csonka, L. N. (1998) Comparative analysis of the regulation of expression and structures of two evolutionarily divergent genes for $\Delta^{1}$-pyrroline-5-carboxylate synthetase from tomato. Plant Physiol. 118, 661-674.

Fourgoux-Nicol, A., Drouaud, J., Haouazine, N., Pelletier, G., and Guerche, P. (1999) Isolation of rapeseed genes expressed early and specifically during development of the male gametophyte. Plant Mol. Biol. 40, 857-872.

Ge, Y. X., Angenent, G. C., Wittich, P. E., Peters, J., Franken, J., Busscher, M., Zhang, L. M., Dahlhaus, E., Kater, M. M., Wullems, G. J., and Creemers-Molenaar T. (2000) NEC1, a novel gene, highly expressed in nectary tissue of Petunia hybrida. Plant J. 24, 725-734.

Ge, Y. X., Angenent, G. C., Dahlhaus, E., Franken, J., Peters, J., Wullems, G. J., and Creemers-Molenaar, J. (2001) Partial silencing of the NEC1 gene results in early opening of anthers in Petunia hybrida. Mol. Genet. Genomics 265, 414-423.

Ginzberg, I., Stein, H., Kapulnik, Y., Szabados, L., Strizhov, N., Schell, J., Koncz, C., and Zilberstein, A. (1998) Isolation and characterization of two different cDNAs of $\Delta^{1}$-pyrroline-5carboxylate synthase in alfalfa, transcriptionally induced upon salt stress. Plant Mol. Biol. 38, 755-764.

Goff, A. S., Ricke, D., Lan, T.-H., Presting, G., Wang, R., Dunn, M., Glazebrook, J., Sessions, A., Oeller, P., Verma, H., Hadley, D., Hutchison, D., Martin, C., Katagiri, F., Lange, B. M., Moughamer, T., Xia, Y., Budworth, P., Zhong, J., Miguel, T., Paszkowski, U., Zhang, S., Colbert, M., Sun, W.1., Chen, L., Cooper, B., Park, S., Wood, T. C., Mao, L., Quail, P., Wing, R., Dean, R., Yu, Y., Zharkikh, A., Shen, R., Sahasrabudhe, S., Thomas, A., Cannings, R., Gutin, A., Pruss, D., Reid, J., Tavtigian, S., Mitchell, J., Eldredge, G.,
Scholl, T., Miller, R. M., Bhatnagar, S., Adey, N., Rubano, T., Tusneem, N., Robinson, R., Feldhaus, J., Macalma, T., Oliphant, A., and Briggs, S. (2002) A draft sequence of the rice genome (Oryza sativa L. ssp. japonica). Science 296, 92-100.

Goldberg, R. B., Beals, T. P., and Sanders, P. M. (1993) Anther development: Basic principles and practical applications. Plant Cell 5, 1217-1229.

Hihara, Y., Hara, C., and Uchimiya, H. (1996) Isolation and characterization of two cDNA clones for mRNAs that are abundantly expressed in immature anthers of rice (Oryza sativa L.). Plant Mol. Biol. 30, 1181-1193.

Honys, D., and Twell, D. (2003) Comparative analysis of the Arabidopsis pollen transcriptome. Plant Physiol. 132, 640652.

Huang, S., An, Y. Q., McDowell, J. M., McKinney, E. C., and Meagher, R. B. (1996) The Arabidopsis thaliana ACT4/ ACT12 actin gene subclass is strongly expressed throughout pollen development. Plant J. 10, 189-202.

Igarashi, Y., Yoshiba, Y., Sanada, Y., Yamaguchi-Shinozaki, K., Wada, K., and Shinozaki, K. (1997) Characterization of the gene for $\Delta^{1}$-pyrroline-5-carboxylate synthetase and correlation between the expression of the gene and salt tolerance in Oryza sativa L. Plant Mol. Biol. 33, 857-865.

Jeon, J. S., Chung, Y. Y., Lee, S., Yi, G. H., Oh, B. G., and An, G. (1999) Isolation and characterization of an anther-specific gene, RA8, from rice (Oryza sativa L.). Plant Mol. Biol. 39, 35-44.

Kamalay, J. C., and Goldberg, R. B. (1980) Regulation of structural gene expression in tobacco. Cell 19, 935-946.

Kamalay, J. C., and Goldberg, R. B. (1984) Organ-specific nuclear RNAs in tobacco. Proc. Natl. Acad. Sci. USA. 81, 2801-2805.

Kaneko, M., Itoh, H., Inukai, Y., Sakamoto, T., Ueguchi-Tanaka, M., Ashikari., M., and Matsuoka, M. (2003) Where do gibberellin biosynthesis and gibberellin signaling occur in rice plants? Plant J. 35, 104-115.

Kapoor, S., Kobayashi, A., and Takatsuji, H. (2002) Silencing of the tapetum-specific zinc finger gene TAZ1 causes premature degeneration of tapetum and pollen abortion in petunia. Plant Cell 14, 2353-2367.

Keijzer, C. J. (1987) The process of anther dehiscence and pollen dispersal. I. The opening mechanism of longitudinally dehiscing anther. New Phytol. 105, 487-498.

Kikuchi, S., Satoh, K., Nagata, T., Kawagashira, N., Doi, K., Kishimoto, N., Yazaki, J., Ishikawa, M., Yamada, H., Ooka, H., Hotta, I., Kojima, K., Namiki, T., Ohneda, E., Yahagi, W., Suzuki, K., Li, C.-j., Ohtsuki, K., Shishiki, T., Otomo, Y., Murakami, K., Iida, Y., Sugano, S., Fujimura, T., Suzuki, Y., Tsunoda, Y., Kurosaki, T., Kodama, T., Masuda, H., Kobayashi, M., Xie, Q., Lu, M., Narikawa, R., Sugiyama, A., Mizuno, K., Yokomizo, S., Niikura, J., Ikeda, R., Ishibiki, J., Kawamata, M., Yoshimura, A., Miura, J., Kusumegi, T., Oka, M., Ryu, R., Ueda, M., Matsubara, K., Kawai, J., Carninci, P., Adachi, J., Aizawa, K., Arakawa, T., Fukuda, S., Hara, A., Hashidume, W., Hayatsu, N., Imotani, K., Ishii, Y., Itoh, M., Kagawa, I., Kondo, S., Konno, H., Miyazaki, A., Osato, N., Ota, Y., Saito, R., Sasaki, D., Sato, K., Shibata, K., Shinagawa, A., Shiraki, T., Yoshino, M., and Hayashizaki, Y. (2003) Collection, mapping, and annotation of over 28,000 cDNA clones from japonica rice. Science 301, 376-379.

Kim, S. R., Kim, Y., and An, G. (1993) Molecular cloning and characterization of anther-preferential cDNA encoding a putative actin-depolymerizing factor. Plant Mol. Biol. 21, $39-45$. 
Koltunow, A. M., Truettner, J., Cox, K. H., Wallroth, M., and Goldberg, R. B. (1990) Different temporal and spatial gene expression patterns occur during anther development. Plant Cell 2, 1201-1224.

Lee, J. Y., and Lee, D. H. (2003) Use of serial analysis of gene expression technology to reveal changes in gene expression in Arabidopsis pollen undergoing cold stress. Plant Physiol. 132, 517-529.

Li, Y., Jones, L., and McQueen-Mason, S. (2003) Expansins and cell growth. Curr. Opin. Plant Biol. 6, 603-610.

Matsuda, N., Tsuchiya, T., Kishitani, S., Tanaka, Y., and Toriyama, K. (1996) Partial male sterility in transgenic tobacco carrying antisense and sense $P A L$ cDNA under the control of a tapetum-specific promoter. Plant Cell Physiol. 37, 215-222.

Matsuda, N., Kishitani, S., and Toriyama, K. (1997) Antisense and sense CHS cDNA expressed by a tapetum-specific promoter causes partial male sterility in transgenic tobacco. Plant Biotech. 14, 157-161.

Matsui, T., Omasa, K., and Horie, T. (1999) Mechanism of anther dehiscence in rice (Oryza sativa L.). Ann. Bot. 84, 501-506.

Millar, A. A., Smith, M. A., and Kunst, L. (2000) All fatty acids are not equal: discrimination in plant membrane lipids. Trends Plant Sci. 95, 95-101.

Niogret, M. F., Dubald, M., Mandaron, P., and Mache, R. (1991) Characterization of pollen polygalacturonase encoded by several cDNA clones in maize. Plant Mol. Biol. 17, 11551164 .

Ogawa, M., Kusano, T., Koizumi, N., Katsumi, M., and Sano, H. (1999) Gibberellin-responsive genes: high level of transcript accumulation in leaf sheath meristematic tissue from Zea mays L. Plant Mol. Biol. 40, 645-657.

Piffanelli, P., Ross, J. H., and Murphy, D. J. (1997) Intra- and extracellular lipid composition and associated gene expression patterns during pollen development in Brassica napus. Plant J. 11, 549-562.

Piffanelli, P., Ross, J. H., and Murphy, D. J. (1998) Biogenesis and function of the lipidic structures of pollen grains. Sex. Plant Reprod. 11, 65-80.

Rubinelli, P., Hu, Y., and Ma, H. (1998) Identification, sequence analysis and expression studies of novel anther-specific genes of Arabidopsis thaliana. Plant Mol. Biol. 37, 607619.

Roberts, M. R., Foster, G. D., Blundell, R. P., Robinson, S. W., Kumar, A., Draper, J., and Scott, R. (1993) Gametophytic and sporophytic expression of an anther-specific Arabidopsis thaliana gene. Plant J. 3, 111-120.

Sasaki, T., and Burr, B. (2000) International Rice Genome Sequencing Project: the effort to completely sequence the rice genome. Curr. Opin. Plant Biol. 3, 138-141.

Schwacke, R., Grallath, S., Breitkreuz, K. E., Stransky, E., Stransky, H., Frommer, W. B., and Rentsch, D. (1999) LeProT1, a transporter for proline, glycine betaine, and $\gamma$ amino butyric acid in tomato pollen. Plant Cell 11, 377392.

Shen, J. B., and Hsu, F. C. (1992) Brassica anther-specific genes: characterization and in situ localization of expression. Mol. Gen. Genet. 234, 379-389.

Showalter, A. M. (1993) Structure and function of plant cell wall proteins. Plant Cell 5, 9-23.

Smith, A. G., Gasser, C. S., Budelier, K. A., and Fraley, R. T. (1990) Identification and characterization of stamen- and tapetum-specific genes from tomato. Mol. Gen. Genet. 222, 9-16.
Sorensen, A. M., Krober, S., Unte, U. S., Huijser, P., Dekker, K., and Saedler, H. (2003) The Arabidopsis ABORTED MICROSPORES (AMS) gene encodes a MYC class transcription factor. Plant J. 33, 413-423.

Takada, Y., Ito, A., Ninomiya, C., Kakizaki, T., Takahata, Y., Suzuki, G., Hatakeyama, K., Hinata, K., Shiba, H., Takayama, S., Isogai, A., and Watanabe, M. (2001) Characterization of expressed genes in the SLL2 region of self-compatible Arabidopsis thaliana. DNA Res. 8, 215-219.

Taylor, L. P., and Hepler, P. K. (1997) Pollen germination and tube growth. Annu. Rev. Plant Physiol. Plant Mol. Biol. 48, 461-491.

Tsuchiya, T., Toriyama, K., Nasrallah, M. E., and Ejiri, S. (1992) Isolation of genes abundantly expressed in rice anthers at the microspore stage. Plant Mol. Biol. 20, 1189-1193.

Tsuchiya, T., Toriyama, K., Ejiri, S. and Hinata, K.1994. Molecular characterization of rice genes specifically expressed in the anther tapetum. Plant Mol. Biol. 26, 1737-1746.

Vauterin, M., Frankard, V., and Jacobs, M. (1999) The Arabidopsis thaliana dhdps gene encoding dihydrodipicolinate synthase, key enzyme of lysine biosynthesis, is expressed in a cell-specific manner. Plant Mol. Biol. 39, 695-708.

Wang, A., Xia, Q., Xie, W., Datla, R., and Selvaraj, G. (2003) The classical Ubisch bodies carry a sporophytically produced structural protein (RAFTIN) that is essential for pollen development. Proc. Natl. Acad. Sci. USA 100, 1448714492.

Weiss, D., van der Luit, A., Knegt, E., Vermeer, E., Mol, J. N. M., and Kooter, J. M. (1995) Identification of endogenous gibberellins in petunia flowers. Plant Physiol. 107, 695702.

Yazaki, J., Kishimoto, N., Nakamura, K., Fujii, F, Shimbo, K., Otsuka, Y., Wu, J., Yamamoto, K., Sakata, K., Sasaki, T., and Kikuchi, S. (2000) Embarking on rice functional genomics via cDNA microarray: use of 3' UTR probes for specific gene expression analysis. DNA Res. 7, 367-370.

Yazaki, J., Kojima, K., Suzuki, K., Kishimoto, N., and Kikuchi, S. (2004) The Rice PIPELINE: a unification tool for plant functional genomics. Nucleic Acids Res. 32, D383-D387.

Yoshiba, Y., Kiyosue, T., Katagiri, T., Ueda, H., Mizoguchi, T., Yamaguchi-Shinozaki, K., Wada, K., Harada, Y., and Shinozaki, K. (1995) Correlation between the induction of a gene for $\Delta^{1}$-pyrroline-5-carboxylate synthetase and the accumulation of proline in Arabidopsis thaliana under osmotic stress. Plant J. 7, 751-760.

Yu, J., Hu, S., Wang, J., Wong, G. K.-S., Li, S., Liu, B., Deng, Y., Dai, L., Zhou, Y., Zhang, X., Cao, M., Liu, J., Sun, J., Tang, J., Chen, Y., Huang, X., Lin, W., Ye, C., Tong, W., Cong, L., Geng, J., Han, Y., Li, L., Li, W., Hu, G., Huang, X., Li, W., Li, J., Liu, Z., Li, L., Liu, J., Qi, Q., Liu, J., Li, L., Li, T., Wang, X., Lu, H., Wu, T., Zhu, M., Ni,, P., Han, H., Dong, W., Ren, X., Feng, X., Cui, P., Li, X., Wang, H., Xu, X., Zhai, W., Xu, Z., Zhang, J., He, S., Zhang, J., Xu, J., Zhang, K., Zheng, X., Dong, J., Zeng, W., Tao, L., Ye, J., Tan, J., Ren, X., Chen, X., He, J., Liu, D., Tian, W., Tian, C., Xia, H., Bao, Q., Li, G., Gao, H., Cao, T., Wang, J., Zhao, W., Li, P., Chen, W., Wang, X., Zhang, Y., Hu, J., Wang, J., Liu, S., Yang, J., Zhang, G., Xiong, Y., Li, Z., Mao, L., Zhou, C., Zhu, Z., Chen, R., Hao, B., Zheng, W., Chen, S., Guo, W., Li, G., Liu, S., Tao, M., Wang, J., Zhu, L., Yuan, L., and Yang, H. (2002) A draft sequence of the rice genome (Oryza sativa L. ssp. indica). Science 296, 79-92.

Zhang, H., Croes, A. F.,, and Linskens, H. F. (1982) Protein synthesis in germinating pollen of Petunia: role of proline. Planta 154, 199-203. 